\title{
Deposition and crystallization studies of thin amorphous solid water films on $\mathrm{Ru}(0001)$ and on CO-precovered $\mathrm{Ru}(0001)$
}

\author{
Takahiro Kondo ${ }^{\text {a) }}$ \\ Institute of material science, University of Tsukuba, 1-1-1 Tennodai, Tsukuba, Ibaraki, 305-8573 Japan \\ and Surface Chemistry Laboratory, RIKEN (The Institute of Physical and Chemical Research), \\ 2-1-1 Hirosawa, Wako, Saitama 351-0198, Japan \\ Hiroyuki S. Kato \\ Surface Chemistry Laboratory, RIKEN (The Institute of Physical and Chemical Research), \\ 2-1-1 Hirosawa, Wako, Saitama, 351-0198 Japan \\ Mischa Bonn \\ FOM Institute for Atomic and Molecular Physics, Kruislaan 407, 1098 SJ Amsterdam, The Netherlands \\ Maki Kawai ${ }^{\text {b) }}$ \\ Surface Chemistry Laboratory, RIKEN (The Institute of Physical and Chemical Research), 2-1-1 Hirosawa, \\ Wako, Saitama, 351-0198 Japan and Department of Advanced Materials Science, \\ University of Tokyo, Kashiwa, Chiba 277-8561, Japan
}

(Received 10 May 2007; accepted 17 July 2007; published online 4 September 2007)

\begin{abstract}
The deposition and the isothermal crystallization kinetics of thin amorphous solid water (ASW) films on both $\mathrm{Ru}(0001)$ and $\mathrm{CO}$-precovered $\mathrm{Ru}(0001)$ have been investigated in real time by simultaneously employing helium atom scattering, infrared reflection absorption spectroscopy, and isothermal temperature-programmed desorption. During ASW deposition, the interaction between water and the substrate depends critically on the amount of preadsorbed CO. However, the mechanism and kinetics of the crystallization of $\sim 50$ layers thick ASW film were found to be independent of the amount of preadsorbed $\mathrm{CO}$. We demonstrate that crystallization occurs through random nucleation events in the bulk of the material, followed by homogeneous growth, for solid water on both substrates. The morphological change involving the formation of three-dimensional grains of crystalline ice results in the exposure of the water monolayer just above the substrate to the vacuum during the crystallization process on both substrates. (C) 2007 American Institute of Physics.
\end{abstract}

[DOI: $10.1063 / 1.2770726]$

\section{INTRODUCTION}

The preparation and detailed characterization of aqueous ice surfaces are essential for a fundamental and detailed understanding of chemical reactions on water ice. When water molecules are deposited on a cold substrate below $120 \mathrm{~K}$ with a slow deposition rate at $<2 \mathrm{~nm} / \mathrm{s}$, low-density amorphous solid water (ASW) is known to form under ultrahigh vacuum conditions. ${ }^{1,2}$ ASW starts to crystallize around the glass transition temperature ${ }^{3-8}$ within an experimentally accessible time scale to form the thermodynamically more stable phase of crystalline ice $(\mathrm{CI}) .^{5-12}$ Both ASW and CI have been observed on planetary bodies and comets, as well as in the interstellar medium and in protoplanetary disks. ${ }^{13,14}$ These ice surfaces are thought to provide the catalytic environment for heterogeneous chemical reactions such as the formation of prebiotic organic molecules in the interstellar medium ${ }^{15}$ and reactions that lead to ozone depletion in the stratosphere. ${ }^{16}$ The deposition and crystallization of ASW and the ice surface morphology have therefore been investigated extensively to further our understanding of chemical reactions on ice surfaces. ${ }^{17-34}$ In this work, we have investi-

\footnotetext{
${ }^{a)}$ Electronic mail: takahiro@riken.jp

${ }^{\mathrm{b}}$ Electronic mail: maki@riken.jp
}

gated the deposition, crystallization mechanism, crystallization kinetics, and morphological change of ASW thin films on both bare $\mathrm{Ru}(0001)$ and CO-precovered $\mathrm{Ru}(0001)$ surfaces (referred to as $\mathrm{CO} / \mathrm{Ru}(0001)$, hereafter), particularly focusing on interfacial effects induced by the preadsorption of $\mathrm{CO}$.

It is well known ${ }^{29-37}$ that ASW layers can exhibit different morphologies and different interactions with the substrate, depending on the precise deposition conditions. An example is the effect on the water layer of substrate modification by the preadsorption of different molecular species such as $\mathrm{CO}, \mathrm{O}_{2}$, and $\mathrm{H}_{2}$. The precise adsorption energy of the first monolayer of water on the metal substrate has been reported to depend critically on the type and amount of the preadsorbed species on the surface. ${ }^{36,37}$ The interaction between the water layer and the substrate has also been reported to affect the growth mode and crystallization mechanism of the upper water layers. ${ }^{18,35-37}$ In order to further clarify the effect of substrate modification on the crystallization mechanism and kinetics, we have here modified the substrate $\mathrm{Ru}(0001)$ surface by controlling the amount of preadsorbed $\mathrm{CO}$ (for coverages ranging from zero to the full coverage). We have investigated the interaction of the water 
layer just above the substrate with the modified $\mathrm{Ru}(0001)$ surface, in addition to the effect of surface modification on the crystallization kinetics.

In principle, the ASW crystallization can be initiated at the ASW surface, in the bulk, or at the ASW-substrate interface. Nucleation at the surface or interface may be energetically favored, because only half a sphere has to be formed in order for the nucleation grain to grow (i.e., the contribution to the height of the activation barrier from the chemical potential difference between CI and ASW and surface tension contributions at the CI-ASW interface are expected to be half compared to the case of the bulk nucleation, where a complete sphere has to be formed). ${ }^{38}$ On the other hand, contributions from the surface tension between the CI core and the vacuum (or the substrate) must be added to the total free energy, in addition to contribution from the line tension at the CI/ASW/vacuum boundary. ${ }^{39}$ These latter terms are strongly influenced by the surface (or interface) morphology of ice films and are unknown. Thus, the mechanism of nucleation cannot be determined a priori. Indeed, not only bulk preferential nucleation ${ }^{17,19,25,29}$ but also the surface preferential nucleation ${ }^{28}$ of CI in ASW films have been reported up to now, depending on the condition of the experiments. Nucleation at the ASW-substrate interface is particularly expected for those substrate materials which exhibit the 'template effect' by providing two-dimensional (2D) nucleation sites for CI. For example, heterogeneous ASW crystallization at the film-substrate interface has been reported when the substrate is the flat $2 \mathrm{D}$ crystalline ice. ${ }^{24,25,29}$ From the lattice matching point of view, the $\mathrm{Ru}(0001)$ surface is one of the best candidates for this template effect because of the small lattice mismatch between the $\mathrm{Ru}(0001)$ substrate and CI. Indeed, the epitaxial growth of $\mathrm{CI}$ on $\mathrm{Ru}(0001)$ has been predicted through the application of the modified Bernal-FowlerPauling rules, ${ }^{35-37}$ though recent studies have proposed that the structure of the water monolayer just above the substrate (referred to as "first water layer" hereafter) differs from the icelike structure at temperatures below the desorption temperature of the first water layer, i.e., $\sim 180 \mathrm{~K} .{ }^{40-50}$ To elucidate the preferential CI nucleation site in the ASW films, it is desirable to independently determine the phase state at the surface, in the bulk, and at the support-water interface of water films during crystallization, as previously demonstrated by Backus et al. ${ }^{28}$

One well-known method of investigating the kinetics of ASW crystallization and the morphology of CI is to monitor the desorption rate of water at a specific temperature [isothermal temperature-programmed desorption (ITPD)] during crystallization. $^{17-21}$ In this method, the conversion from ASW to CI is determined from the change in the desorption rate of water due to different activation barriers of water desorption from ASW and from CI. ${ }^{19,29}$ Quite recently, however, a different interpretation of the ITPD signal was proposed based on time-of-flight secondary ion mass spectroscopy. ${ }^{51,52}$ In these reports, the change in desorption rate was attributed to morphological changes in the ASW film and/or a phase transformation of ASW to the liquid/ supercooled-liquid phase rather than to ASW crystallization.
A simultaneous measurement of the ITPD signal and the phase state of the water layer would conclusively demonstrate which interpretation is correct.

Another debated issue concerns the surface morphology of CI, which has been examined through the water desorption rate after completion of the crystallization process by ITPD. ${ }^{17-20}$ Different surface morphologies of CI have been reported, depending on the wetting properties of the substrate and the initial water film thickness. For example, the zeroorder desorption observed for water desorption from thin CI films on $\mathrm{Pt}(111)$ was interpreted as the result of the uniform surface morphology of CI owing to the hydrophilic nature of Pt(111). ${ }^{18-20}$ However, an unexpected morphological change in a CI film on $\mathrm{Pt}(111)$ has been reported recently, based on measurements of $\mathrm{Kr}$ desorption from the ice surface. ${ }^{22}$ The final water monolayer, which interacts relatively strongly with the $\mathrm{Pt}(111)$ substrate (first water layer), ${ }^{36,37}$ becomes exposed to the vacuum during zero-order desorption of water from CI after crystallization has been completed, ${ }^{22}$ but while many water layers remain on the surface.

In the present work, to address the aforementioned issues and further investigate the crystallization of ASW in detail, the isothermal crystallization process of ASW layers of $\mathrm{D}_{2} \mathrm{O}$ on both $\mathrm{Ru}(0001)$ and $\mathrm{CO} / \mathrm{Ru}(0001)$ has been investigated. Our real-time study employs $\mathrm{He}$ atom scattering (HAS), infrared reflection absorption spectroscopy (IRAS), and ITPD. These three surface probes are used simultaneously in parallel. The HAS and IRAS combination is completely noninvasive, causing no damage to the delicate hydrogen-bonded water network. Changes in the surface and bulk phase state are evident from changes in the ITPD and changes in the vibrational response of water in the IRAS spectra, respectively. HAS is sensitive to changes in surface morphology, such as the appearance of crystalline and/or first water layer domains exposed to the vacuum. We have already reported preliminary results of the ASW crystallization in the case of the $\mathrm{Ru}(0001)$ substrate, quite recently. ${ }^{53}$ The new results reported in the present article further support our previous conclusions and extend these studies to the COmodified surface.

In this article, we first report the interaction of water with $\mathrm{CO} / \mathrm{Ru}(0001)$ depending on the coverage of water and preadsorbed CO. Second, we discuss the mechanism and kinetics of the ASW crystallization on both $\mathrm{Ru}(0001)$ and on $\mathrm{CO} / \mathrm{Ru}(0001)$ in detail. We then discuss the morphological change and the exposure of the first water layer to the vacuum which occurs during the crystallization of ASW. Finally we discuss and summarize the effect of the interface modification by the $\mathrm{CO}$ preadsorption on the deposition and the crystallization of $\mathrm{ASW}$ on $\mathrm{Ru}(0001)$.

\section{EXPERIMENT}

The experimental apparatus used in this work has already been described elsewhere. ${ }^{54}$ In this article, therefore, we will limit ourselves to the description of newly developed/attached systems and measurement conditions/ methods.

The apparatus consists of five stainless-steel chambers, 
each of which is evacuated independently to ultrahigh vacuum (UHV). The supersonic He beam is generated by free-jet expansion from the nozzle and then skimmed by the skimmer. The specularly reflected $\mathrm{He}$ (incident translational energy: $63 \mathrm{meV}$ ) with a scattering angle of $45^{\circ}$ with respect to the sample surface normal is detected by the quadrupole mass spectrometer (QMS) with two differential pumping stages (the measurement is referred to as HAS hereafter). The scattered He atoms, detected by the QMS, are counted by a pulse counter after amplification and noise discrimination. The diffraction profile of the He beam is measured by rotating the sample along the axis perpendicular to the scattering plane (beam line) with an angular accuracy better than $\pm 0.1^{\circ}$.

The infrared light produced by the light source in the Fourier transform IR spectrometer (JASCO FT/IR-550) is $p$ polarized through a $\mathrm{ZnSe}$ polarizer. It is then focused onto the sample surface in the UHV chamber by a concave mirror through the $\mathrm{BaF}$ view port at an $85^{\circ}$ grazing angle of incidence. The IR-light specularly reflected from the sample is detected by a mercury-cadmium-telluride (MCT) detector. The light paths outside the UHV chamber are purged by pure nitrogen gas to avoid the absorption by ambient air, which contains $\mathrm{CO}_{2}$ and $\mathrm{H}_{2} \mathrm{O}$. IRAS spectra were recorded at $4 \mathrm{~cm}^{-1}$ resolution with 20 scan $(40 \mathrm{~s})$ averages. The IR absorbance $A$ is defined as $A=-\ln \left(R / R_{0}\right)$, where $R$ and $R_{0}$ are the reflected intensities with and without the water layers on the substrate, respectively.

The QMS used for the temperature-programmed desorption (TPD) and ITPD is located in front of the sample. The ionization volume of the QMS is enclosed in a home-built small cup, which increases the signal-to-noise ratio. To prevent damage to the water layers by stray electrons from the QMS ionizer, the sample was held at $-160 \mathrm{~V}$ bias during the experiment.

The $\mathrm{Ru}(0001)$ surface was cleaned using standard sputtering, annealing, oxidation, and flashing cycles in the UHV chamber with a base pressure of $\sim 1 \times 10^{-10}$ Torr. The temperature of the sample surface is measured by $C$-type (W5\% Re-W26\% Re) and $K$-type (alumel-chromel) thermocouples spot welded to the edge of crystal. Each of the output Seebeck voltages is measured by a digital multimeter, referenced to liquid nitrogen temperature. The substrate temperature was then carefully calibrated by TPD measurements of $\mathrm{D}_{2} \mathrm{O}$ from $\mathrm{Ru}(0001)$ prior to the experiments. ${ }^{55}$

The thickness of the water layer is expressed in monolayers (ML). $1 \mathrm{ML}$ is defined as the amount of water adsorbed on the $\mathrm{Ru}(0001)$ surface that, in a thermal desorption experiment, gives rise to one desorption feature near $180 \mathrm{~K}$. This feature saturates with exposure, after which multilayer desorption occurs near $160 \mathrm{~K} .{ }^{55}$ Thin films of ASW of 50 ML (an order of magnitude larger than the estimated critical nucleus $\operatorname{size}^{20}$ ) were deposited on the surface at $\sim 90 \mathrm{~K}$ via backfill vapor deposition, where the sticking probability of $\mathrm{D}_{2} \mathrm{O}$ on the surface is assumed to be 1.0 for estimating the layer thickness based on the dosed amount. This deposition method is known to result in relatively smooth and uniform ice multilayers. ${ }^{19,31}$ The kinetics of crystallization are known to depend strongly on layer thickness. ${ }^{17-20}$ For this reason, we report here the kinetics for a fixed initial thickness of $\sim 50$ ML. After the deposition of ASW, the layers were heated at a rate of $\sim 0.2 \mathrm{~K} / \mathrm{s}$ to the designated temperature at which ITPD, IRAS, and HAS measurements were performed simultaneously.

We investigated fully deuterated water $\left(\mathrm{D}_{2} \mathrm{O}\right)$ because the IR spectrometer has a better sensitivity at O-D stretch frequencies than at $\mathrm{O}-\mathrm{H}$ stretch frequencies. Whether the $\mathrm{D}_{2} \mathrm{O}$ multilayer is present as ASW or CI can be determined directly through the O-D stretching vibrational mode $\left(\nu_{\mathrm{OD}}\right)$ of water in the IRAS spectrum as demonstrated previously for $\mathrm{H}_{2} \mathrm{O} .^{28}$ The IRAS spectra $I(\nu)$ measured during the ASW crystallization can be very well reproduced by a fitting analysis with sum of contributions from amorphous domains $I_{\mathrm{ASW}}(\nu)$, (viz., the spectrum at $t=0$ ) and crystalline domains $I_{\mathrm{CI}}(\nu)$ (the spectrum after heating for long time, for which the spectral shape of the IR absorption remains unchanged) as reported in the literature. ${ }^{28,53}$ Here, $I(\nu)$ is represented as

$$
I(\nu)=a \sigma_{\mathrm{CI}} I_{\mathrm{CI}}(\nu)+b \sigma_{\mathrm{ASW}} I_{\mathrm{ASW}}(\nu),
$$

where $a$ and $b$ are the fractions of crystalline and amorphous ice (both values can be derived from the fitting analysis), respectively, and $\sigma_{\mathrm{CI}}$ and $\sigma_{\mathrm{ASW}}$ are the respective cross sections of the vibrational response for ASW and CI, each depending on the geometric configuration of the water molecules due to the selection rule of IRAS on metal surface. ${ }^{56}$ The cross sections are related as $\sigma_{\mathrm{ASW}}=0.67 \times \sigma_{\mathrm{CI}}$, based on the comparison of the IRAS spectra with the amount of the corresponding water molecules obtained from TPD. ${ }^{28}$ The "converted fraction" is defined here as the crystalline contribution divided by the weighted sum of the two, i.e., $a \sigma_{\mathrm{CI}} /\left(a \sigma_{\mathrm{CI}}+b \sigma_{\mathrm{ASW}}\right)$. The detail of the spectrum shape each of ASW and CI will be discussed in Sec. III D.

\section{RESULTS AND DISCUSSIONS}

\section{A. CO adsorption on $\mathrm{Ru}(\mathbf{0 0 0 1 )}$}

A simultaneous and in situ observation of both HAS and IRAS signals from $\mathrm{Ru}(0001)$ at $\sim 155 \mathrm{~K}$ during $\mathrm{CO}$ dosing are shown in Figs. 1(a) and 1(b), respectively. The sticking probability of $\mathrm{CO}$ on $\mathrm{Ru}(0001)$ is known to depend on the CO coverage $\left(\theta_{\mathrm{CO}}\right)$, incident translational energy of $\mathrm{CO}$, and surface temperature. ${ }^{57,58}$ Therefore, it is not easy to directly convert the horizontal axis of Fig. 1(a) to the exact $\theta_{\mathrm{CO}}$. We can, however, indicate distinct adsorption structures on the surface based on separately conducted helium atom diffraction measurements as indicated by the arrows in Fig. 1(a).

With increasing $\mathrm{CO}$ dosing up to $\sim 0.5 \mathrm{~L}$, the He intensity specularly reflected from the surface decreases. This indicates an increase of the corrugation of the interaction potential between $\mathrm{He}$ and the surface ${ }^{59-61}$ due to the ordered $(\sqrt{3} \times \sqrt{3}) \mathrm{R} 30^{\circ}-\mathrm{CO}$ formation on $\mathrm{Ru}(0001)$ (ideal coverage: $\left.\theta_{\mathrm{CO}}=\sim 0.33 \mathrm{ML}\right)$. The absorption of infrared light by the $\mathrm{CO}$ stretching vibrational mode $\left(\nu_{\mathrm{CO}}\right)$ on $\mathrm{Ru}(0001)$ appears in the IRAS signal at $\sim 2018 \mathrm{~cm}^{-1}$ as $\mathrm{CO}$ dosing is initiated, as shown in Fig. 1(b), and it shows a continuous blueshift with increasing $\mathrm{CO}$ dose as reported previously. ${ }^{62,63} \mathrm{CO}$ is known to adsorb in an upright geometry ${ }^{64,65}$ on top of a Ru atom, at least up to the coverage of $\theta_{\mathrm{CO}}=0.33 \mathrm{ML}$ at temperatures 
CO dose [L]
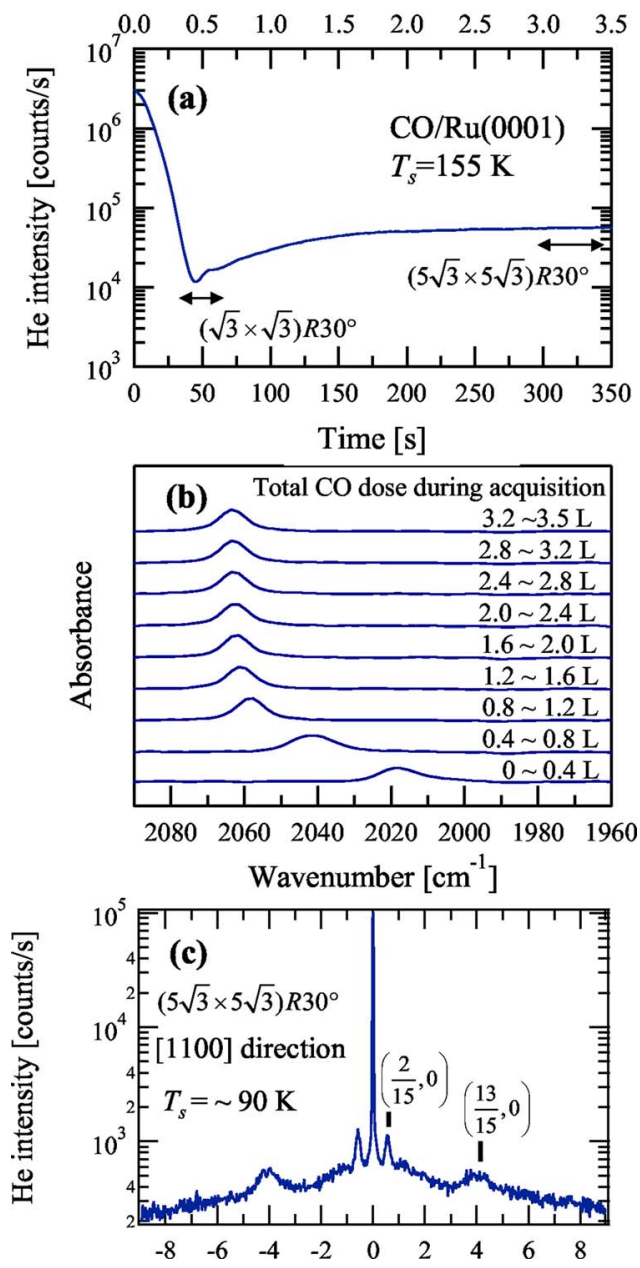

FIG. 1. (Color online) Simultaneous acquisition of (a) HAS and (b) IRAS on $\mathrm{Ru}(0001)$ during $\mathrm{CO}$ dosing with $0.01 \mathrm{~L} / \mathrm{s}$. (c) Helium atom diffraction profile at the $(5 \sqrt{3} \times 5 \sqrt{3}) \mathrm{R} 30^{\circ}-\mathrm{CO} / \mathrm{Ru}(0001)$ surface along the [1000] azimuthal direction (incident wavevector of He beam is $11 \AA^{-1}$ ).

below the desorption temperature. ${ }^{66-68}$ Bonding at top sites occurs via a charge transfer from the $5 \sigma$ orbital of $\mathrm{CO}$ to the metal and a backdonation from the metal into the antibonding $2 \pi^{*}$ orbital of $\mathrm{CO} .{ }^{69,70}$ The continuous blueshift of $\nu_{\mathrm{CO}}$ observed up to $\theta_{\mathrm{CO}}=0.33 \mathrm{ML}$ has been interpreted to be due to lateral dipole coupling, ${ }^{62,63}$ while the weakening of the bond between $\mathrm{CO}$ and the surface is also considered to occur and induce larger blueshift at coverages exceeding 0.33 ML. ${ }^{63}$

With a further increase of $\mathrm{CO}$ dose above $0.5 \mathrm{~L}$ $\left(\theta_{\mathrm{CO}}=\sim 0.33 \mathrm{ML}\right)$, the He intensity gradually and slightly increases up to the complete formation of the saturated structure of $(5 \sqrt{3} \times 5 \sqrt{3}) \mathrm{R} 30^{\circ}-\mathrm{CO} / \mathrm{Ru}(0001)$, indicating the decrease of the corrugation of the interaction potential between $\mathrm{He}$ and the surface. The He atom diffraction profile along the [1000] azimuthal direction observed at $\sim 90 \mathrm{~K}$ after $\sim 20 \mathrm{~L}$ exposure at $155 \mathrm{~K}$ is shown in Fig. 1(c), which has the same diffraction peaks of $(5 \sqrt{3} \times 5 \sqrt{3}) \mathrm{R} 30^{\circ}-\mathrm{CO} / \mathrm{Ru}(0001)$ reported in the literature. ${ }^{71}$ Note that the diffraction peaks appeared at $\sim 0.55$ and $\sim 4.0 \AA^{-1}$ are not the integral-order spots but the fractional-order spots of $(2 / 15,0)$ and $(13 / 15,0)$, respectively. The peak heights and widths ob- served in Fig. 1(c) are quite similar to those reported in the literature. ${ }^{71}$ As shown in Fig. 1(b), in correspondence with the HAS results, the blueshift of $\nu_{\mathrm{CO}}$ is saturated at $2064 \mathrm{~cm}^{-1}$ as reported in the literature. ${ }^{62}$

When $\mathrm{CO}$ adsorbs on the transition metal surface, a significant amount of the diffuse scattering of He is known to occur. Thus, $\mathrm{CO}$ has been treated as a "perfect diffuse scatterer" with a large scattering cross section for the diffuse scattering of thermal energy He atoms. ${ }^{59-61,72}$ In contrast, our HAS apparatus has sufficient dynamic range to monitor the formation of $\mathrm{CO}$ superstructures on the $\mathrm{Ru}(0001)$ surface as shown in Fig. 1 owing to the efficient differential pumping stages for the detector. This is a great advantage to monitor the surface morphological change at the relatively highly corrugated surface with high sensitivity.

\section{B. $\mathrm{D}_{2} \mathrm{O}$ adsorption}

Simultaneous and in situ observations of HAS and IRAS during $\mathrm{D}_{2} \mathrm{O}$ dosing with $2.5 \times 10^{-3} \mathrm{~L} / \mathrm{s}$ on $\mathrm{Ru}(0001)$, $(\sqrt{3} \times \sqrt{3}) \mathrm{R} 30^{\circ}-\mathrm{CO} / \mathrm{Ru}(0001) \quad\left(\theta_{\mathrm{CO}}=0.33 \quad \mathrm{ML}\right), \quad$ and $(5 \sqrt{3} \times 5 \sqrt{3}) \mathrm{R} 30^{\circ}-\mathrm{CO} / \mathrm{Ru}(0001)\left(\theta_{\mathrm{CO}}=0.65 \mathrm{ML}\right)$ at $\sim 95 \mathrm{~K}$ are shown in Fig. 2. In every case, the specularly reflected $\mathrm{He}$ intensity decreases with increasing $\mathrm{D}_{2} \mathrm{O}$ dosing, indicating an increase of the corrugation of the interaction potential between $\mathrm{He}$ and the surface as a result of $\mathrm{D}_{2} \mathrm{O}$ adsorption. However, for $\theta_{\mathrm{CO}}=0$ and $0.33 \mathrm{ML}$ a transient increase in the HAS intensity is observed at $\sim 1$ and $\sim 0.5 \mathrm{~L}$ water doses, respectively. At a water dose of $\sim 3.5 \mathrm{~L}(\sim 1400 \mathrm{~s})$, the $\mathrm{He}$ intensity decreases down to the background count level for all three substrates, where the specularly reflected He signal cannot be resolved from a broad scattering component. This indicates the formation of a very highly corrugated/ disordered surface structure. Indeed, the surface of ASW has been characterized as such. ${ }^{73}$ At coverages of $\mathrm{D}_{2} \mathrm{O}$ exceeding $\theta_{\mathrm{D}_{2} \mathrm{O}} \sim 5 \mathrm{ML}$, the He intensity has reached plateaus and the shapes of the IRAS spectra are the same for all substrates. In what follows, we describe detailed adsorption features of $\mathrm{D}_{2} \mathrm{O}$ depending on the substrate observed from submonolayer to a few layers of $\mathrm{D}_{2} \mathrm{O}$, i.e., the range depicted in Fig. 2.

\section{1. $\mathrm{D}_{2} \mathrm{O}$ on $\mathrm{Ru}(0001)$}

On the clean $\mathrm{Ru}(0001)$ surface, Fig. 2(a), a transient maximum in the HAS signal is observed at $\sim 1.0 \mathrm{~L}$ exposure $(\sim 400 \mathrm{~s})$, indicating the formation of the ordered $(\sqrt{3} \times \sqrt{3}) \mathrm{R} 30^{\circ}-\mathrm{D}_{2} \mathrm{O} / \mathrm{Ru}(0001)$ overlayer. ${ }^{55}$ The maximum $\mathrm{He}$ intensity at this point is larger than what we reported previously ${ }^{55}$ because the deposition rate of $\mathrm{D}_{2} \mathrm{O}$ in Fig. 2 is much smaller compared to our previous report. The slow deposition apparently enables the $\mathrm{D}_{2} \mathrm{O}$ molecules to attain a more ordered structure, presumably by enabling the molecules to diffuse to the energetically most stable sites prior to further $\mathrm{D}_{2} \mathrm{O}$ deposition on neighboring sites which possibly inhibits diffusion by forming hydrogen-bonded networks among the $\mathrm{D}_{2} \mathrm{O}$ molecules. This interpretation is corroborated by the observation that the maximum scattered $\mathrm{He}$ intensity at $\sim 1 \mathrm{~L}$ dosing can also be modified by changing the surface temperature during dosing (from 80 to $130 \mathrm{~K}$ ). Irre- 

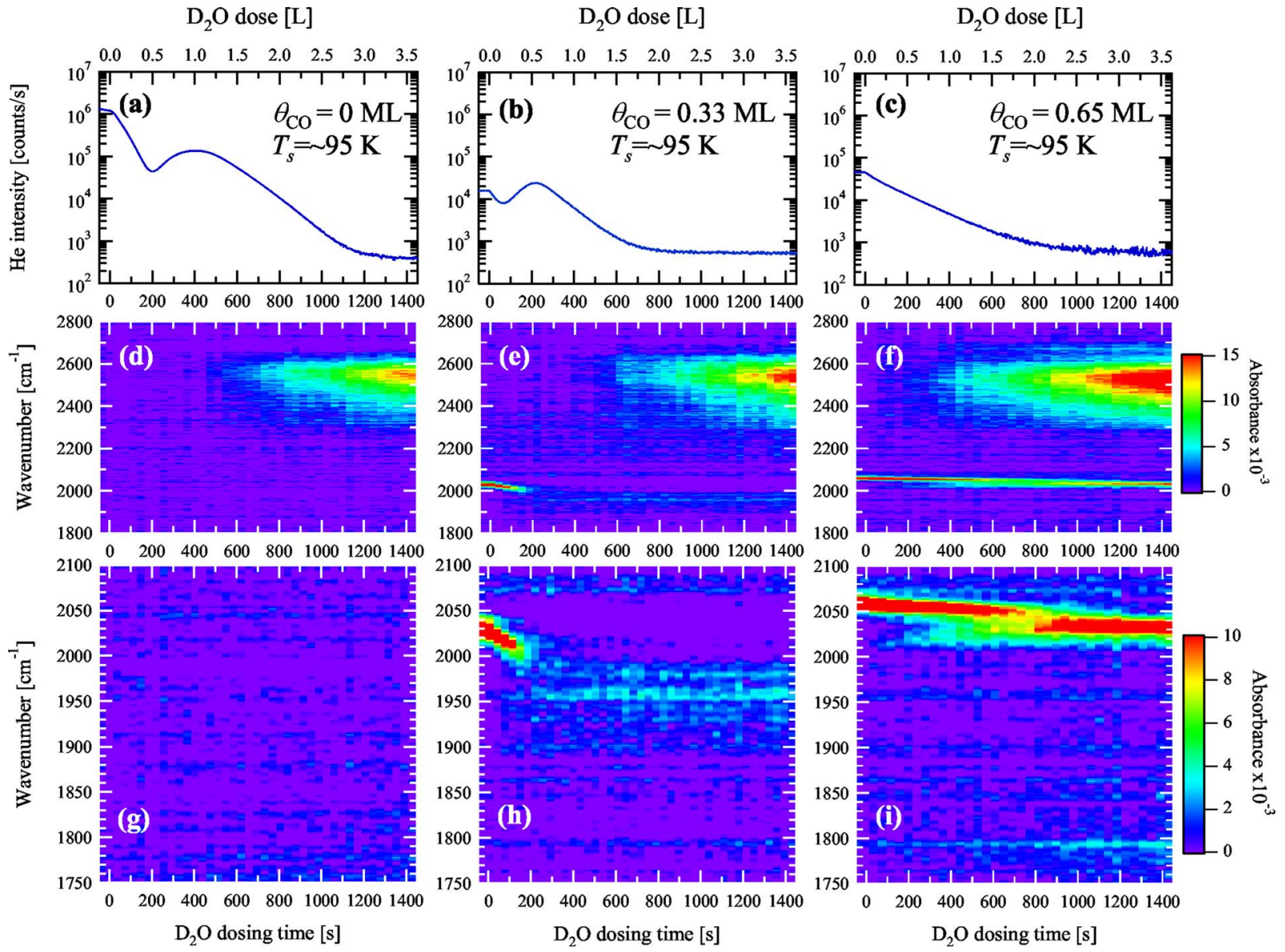

FIG. 2. (Color online) Simultaneous acquisition of HAS and IRAS during $\mathrm{D}_{2} \mathrm{O}$ dosing with $2.5 \times 10^{-3} \mathrm{~L} / \mathrm{s}$ on [(a), (d), and (g) $] \mathrm{Ru}(0001)$, [(b), (e), and (h)] $(\sqrt{3} \times \sqrt{3}) \mathrm{R} 30^{\circ}-\mathrm{CO} / \mathrm{Ru}(0001)$, and $[(\mathrm{c})$, (f), and (i) $]$ on $(5 \sqrt{3} \times 5 \sqrt{3}) \mathrm{R} 30^{\circ}-\mathrm{CO} / \mathrm{Ru}(0001)$.

spective of the dosing conditions (deposition rate and temperature), the specularly reflected intensity of $\mathrm{He}$ from $\mathrm{D}_{2} \mathrm{O} / \mathrm{Ru}(0001)$ at $\theta_{\mathrm{D}_{2} \mathrm{O}}=1.0 \mathrm{ML}$ can always be brought to the same level by annealing the surface. After annealing, a distinct diffraction profile can be observed, as we reported previously. ${ }^{55}$

With increasing $\mathrm{D}_{2} \mathrm{O}$ dose, a wide absorption peak in the range $2400-2600 \mathrm{~cm}^{-1}$ appears in the time-resolved IRAS spectra, for doses exceeding $\sim 1.0 \mathrm{~L}$ [Fig. 2(d)]. This is the typical absorption peak of the OD stretching vibrational mode $\left(\nu_{\mathrm{OD}}\right)$ of $\mathrm{D}_{2} \mathrm{O}$ forming a hydrogen-bonded network, where intra- and intermolecular couplings among $\mathrm{D}_{2} \mathrm{O}$ molecules cause a large peak width of $\nu_{\mathrm{OD}}{ }^{73,74}$

No absorption peak can be discerned at 2670, 2730, and $2750 \mathrm{~cm}^{-1}$ contrary to the case on $(5 \sqrt{3} \times 5 \sqrt{3}) \mathrm{R} 30^{\circ}-\mathrm{CO} /$ $\mathrm{Ru}(0001)$ shown in Fig. 2(f). These relatively high-frequency resonances have been assigned to $\nu_{\mathrm{OD}}$ of $\mathrm{D}_{2} \mathrm{O}$ having an $\mathrm{OD}$ group pointing up toward the vacuum, which does not contribute to the hydrogen bond (the so-called dangling OD) ${ }^{73,75}$ The weak intensity of $\nu_{\mathrm{OD}}$ (dangling OD) on $\mathrm{Ru}(0001)$ at $\theta_{\mathrm{D}_{2} \mathrm{O}}<1.0 \mathrm{ML}$ has also been observed in sumfrequency generation measurement ${ }^{76}$ and by IRAS measurements from the group of Haq et al. ${ }^{49}$ as well as our group. ${ }^{77}$ Based on density functional theory, IRAS measurements, low energy electron diffraction results, TPD, and work function measurements in literature, the group of Haq et al. has recently proposed ${ }^{49}$ chains of intact water as the structure of the first layer on $\mathrm{Ru}(0001)$, which is different from bulk icelike structure, dissociated phase $\left(\mathrm{OD}+\mathrm{D}_{2} \mathrm{O}\right.$ phase $),{ }^{41,42}$ and previously proposed first layer models ${ }^{35,40-48}$ but agrees well with most of the experimental observations up to now.

\section{2. $\mathrm{D}_{2} \mathrm{O}$ on $(\sqrt{3} \times \sqrt{3}) \mathrm{R} 30^{\circ}-\mathrm{CO} / \mathrm{Ru}(0001)$}

As in the case of clean $\mathrm{Ru}(0001)$, a maximum appears in the $\mathrm{He}$ intensity during $\mathrm{D}_{2} \mathrm{O}$ dosing on the $(\sqrt{3}$ $\times \sqrt{3})-\mathrm{R} 30^{\circ}-\mathrm{CO} / \mathrm{Ru}(0001)$ surface, as shown in Fig. 2(b). However the $\mathrm{D}_{2} \mathrm{O}$ dose at which the maximum appears is much smaller, i.e., $\sim 0.5 \mathrm{~L}(\sim 200 \mathrm{~s})$. The maximum intensity of the bump is slightly larger than the initial intensity, indicating formation of an ordered structure such as the proposed $(2 \times 2)-\left(2 \mathrm{CO}+\mathrm{D}_{2} \mathrm{O}\right) / \mathrm{Ru}(0001)$ structure ${ }^{78,79}$ with a relatively smooth potential corrugation between $\mathrm{He}$ and the surface, although we did not conduct an independent measurement to confirm the exact surface structure at this moment.

During the appearance of the bump in HAS, the vibrational frequency of the underlying $\mathrm{CO}, \nu_{\mathrm{CO}}$, in IRAS shifts continuously towards lower frequencies as shown in Fig. 2(h). The continuous redshift of $\nu_{\mathrm{CO}}$ is considered to be induced by the reduction of the lateral dipole interaction among $\mathrm{CO}$ molecules adsorbed on top site of $\mathrm{Ru}$. The intensity of $\nu_{\mathrm{CO}}$ becomes weak at $\sim 1980 \mathrm{~cm}^{-1}$ by $\mathrm{D}_{2} \mathrm{O}$ dosing of $\sim 0.5 \mathrm{~L}(\sim 200 \mathrm{~s})$, while peaks at $\sim 1960$ and $\sim 1790 \mathrm{~cm}^{-1}$ 


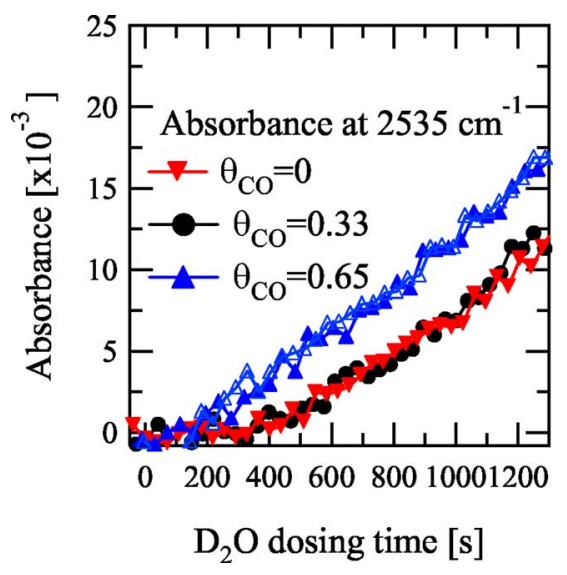

FIG. 3. (Color online) The line profile of the absorbance at $2535 \mathrm{~cm}^{-1}$ (peak intensity of the OD stretching vibrational mode) as a function of $\mathrm{D}_{2} \mathrm{O}$ dosing time. (Inverse solid triangle) $\theta_{\mathrm{CO}}=0 \mathrm{ML}$. (Solid circle) $\theta_{\mathrm{CO}}=0.33 \mathrm{ML}$. (Solid/open triangle) Two measurements at $\theta_{\mathrm{CO}}=0.65 \mathrm{ML}$ demonstrating the reproducibility.

appear simultaneously as shown in Fig. 2(h). These additional peaks can be assigned to $\nu_{\mathrm{CO}}$ of the $\mathrm{CO}$ molecule at a bridge site ${ }^{80}$ and at a threefold-hollow site, ${ }^{79,80}$ respectively. The majority of the $\mathrm{CO}$ molecules adsorbed on $\mathrm{Ru}(0001)$ are therefore considered to shift from the on-top site to the bridge and threefold-hollow sites upon $\mathrm{D}_{2} \mathrm{O}$ adsorption. It is likely that the on-top site of $\mathrm{Ru}$ becomes occupied by $\mathrm{D}_{2} \mathrm{O}$ molecules forming a hybridized state between an oxygen lone-pair $1 b_{1}$ orbital and the Ru $4 d_{z 2}$ orbital, as in the case of clean $\mathrm{Ru}(0001){ }^{42}$ The IRAS spectra in the $\nu_{\mathrm{OD}}$ region shown in Fig. 2(e) clearly supports this view. The absorption profile of $\nu_{\mathrm{OD}}$ region on $(\sqrt{3} \times \sqrt{3}) \mathrm{R} 30^{\circ}-\mathrm{CO} / \mathrm{Ru}(0001)$ is quite similar to the case on $\mathrm{Ru}(0001)$ which is discussed in Sec. III B 1 and distinctly different from the case on $(5 \sqrt{3} \times 5 \sqrt{3}) \mathrm{R} 30^{\circ}-\mathrm{CO} / \mathrm{Ru}(0001)$ shown in Fig. 2(f).

Above $\sim 1.25 \mathrm{~L}(\sim 500 \mathrm{~s})$, the absorption profile of $\nu_{\mathrm{CO}}$ remains the same, although the $\nu_{\mathrm{OD}}$ intensity increases continuously with increasing $\mathrm{D}_{2} \mathrm{O}$ dosing, which indicates a structurally stable interface between the ASW films and the substrate during water deposition.

\section{3. $\mathrm{D}_{2} \mathrm{O}$ on $(5 \sqrt{3} \times 5 \sqrt{3}) \mathrm{R} 30^{\circ}-\mathrm{CO} / \mathrm{Ru}(0001)$}

The adsorption features of $\mathrm{D}_{2} \mathrm{O}$ on $(5 \sqrt{3} \times 5 \sqrt{3}) \mathrm{R} 30^{\circ}$ $-\mathrm{CO} / \mathrm{Ru}(0001)$ are quite different from those on $\mathrm{Ru}(0001)$ and on $(\sqrt{3} \times \sqrt{3})-\mathrm{R} 30^{\circ}-\mathrm{CO} / \mathrm{Ru}(0001)$. First, there is no transient maximum in the HAS intensity as shown in Fig. 2(c), indicating that the corrugation of the interaction potential between the $\mathrm{He}$ atoms and the surface increases continuously with water coverage. No superstructures consisting of coadsorbed $\mathrm{D}_{2} \mathrm{O}$ and $\mathrm{CO}$ appear to be formed during $\mathrm{D}_{2} \mathrm{O}$ dosing. Second, the initial $\nu_{\mathrm{OD}}$ intensity appears already at much lower coverages for water on the $(5 \sqrt{3} \times 5 \sqrt{3}) \mathrm{R} 30^{\circ}$ $-\mathrm{CO} / \mathrm{Ru}(0001)$ surface. The peak intensity of $\nu_{\mathrm{OD}}$ at $2535 \mathrm{~cm}^{-1}$ is shown in Fig. 3 as a function of $\mathrm{D}_{2} \mathrm{O}$ dosing time for the three substrates. The absorbance intensity becomes nonzero at $\sim 200 \mathrm{~s}(0.5 \mathrm{~L})$ for $\theta_{\mathrm{CO}}=0.65 \mathrm{ML}$, while the increases commence at $\sim 400 \mathrm{~s}(\sim 1.0 \mathrm{~L})$ for both $\theta_{\mathrm{CO}}$ $=0 \mathrm{ML}$ and $\theta_{\mathrm{CO}}=0.33 \mathrm{ML}$. These results suggest that $\mathrm{D}_{2} \mathrm{O}$ is infrared inactive ${ }^{56}$ (with an $\mathrm{O}-\mathrm{D}$ bond parallel to the surface) at low coverage on both the clean $\mathrm{Ru}(0001)$ and the $(\sqrt{3} \times \sqrt{3}) \mathrm{R} 30^{\circ}-\mathrm{CO} / \mathrm{Ru}(0001)$ surfaces. On the $(5 \sqrt{3}$ $\times 5 \sqrt{3}) \mathrm{R} 30^{\circ}-\mathrm{CO} / \mathrm{Ru}(0001)$ surface, in contrast, this is not the case. The appearance of the $\nu_{\mathrm{OD}}$ (dangling OD) peak at $2670 \mathrm{~cm}^{-1}$ for water on the $(5 \sqrt{3} \times 5 \sqrt{3}) \mathrm{R} 30^{\circ}$ $-\mathrm{CO} / \mathrm{Ru}(0001)$ surface [Fig. 2(f)] evidently supports this view. Also, the $\mathrm{C}-\mathrm{O}$ stretch intensity $\nu_{\mathrm{CO}}$ above $2000 \mathrm{~cm}^{-1}$ is still large even after the $\mathrm{D}_{2} \mathrm{O}$ adsorption above $1.0 \mathrm{~L}$ $(>\sim 400 \mathrm{~s})$, suggesting that the majority of $\mathrm{CO}$ molecules cannot be displaced by water from the on-top site of $\mathrm{Ru}(0001)$ contrary to the case on $\theta_{\mathrm{CO}}=0.33 \mathrm{ML}$ as discussed in Sec. III B 2. Only a part of the CO molecules is considered to migrate from on-top sites to threefold hollow sites as evidenced by the appearance of the weak absorption peak at $1785 \mathrm{~cm}^{-1}$ (Refs. 79 and 80) as shown in Fig. 2(i). Because $\mathrm{CO}$ occupies most of on-top sites on $\mathrm{Ru}(0001), \mathrm{D}_{2} \mathrm{O}$ may not directly adsorb at the on-top site in the case of $\theta_{\mathrm{CO}}=0.65 \mathrm{ML}$ and thus needs to adsorb in a different geometry, possibly forming water clusters with hydrogen bond network on the CO-precovered surface as evidenced by the early onset of the increase of $\nu_{\mathrm{OD}}$ intensity as shown in Fig. 3.

The large intensity of $\nu_{\mathrm{CO}}$ even at high $\mathrm{D}_{2} \mathrm{O}$ coverage makes this system a good candidate for monitoring the interface condition during crystallization of ASW by way of monitoring the change of $\nu_{\mathrm{CO}} \cdot{ }^{28}$ Thus, we have selected this high coverage condition as a sample of the $\mathrm{CO} / \mathrm{Ru}(0001)$ surface. The desorption and the crystallization of $\mathrm{D}_{2} \mathrm{O}$ on $\mathrm{CO} / \mathrm{Ru}(0001)$ discussed from next section are, therefore, limited to this high coverage $\theta_{\mathrm{CO}}$ condition.

\section{C. $\mathrm{D}_{2} \mathrm{O}$ desorption}

The investigation of water desorption from the surface is important to understand the interaction between water and the surface in detail and thus a number of TPD measurements have been reported up to now for adsorbed water on several substrates. ${ }^{36,37}$ The $\mathrm{Ru}(0001)$ surface has been one of the most controversial substrates and the nature of the first water layer structure has been much debated, mainly due to the exceptionally high dissociation probability of adsorbed water due to ambient electrons (see Ref. 50 and references therein). Taking care to avoid ambient electrons impinging onto the surface, only two desorption peaks can be observed in TPD of $\mathrm{D}_{2} \mathrm{O}$ from $\mathrm{Ru}(0001)$ (Ref. 50) as we reported previously. ${ }^{55,77}$ The first peak appearing at $\sim 160 \mathrm{~K}$ is assigned to a desorption peak of multilayer water, which shows zero-order desorption kinetics ${ }^{81}$ as evidenced by the common leading edge unless crystallization occurs. The second peak appearing at $\sim 180 \mathrm{~K}$ is thought of as a desorption peak of the first water layer which interacts relatively strongly with the substrate. These two peaks are observed on most transition metal surfaces, ${ }^{36,37}$ which indicates the existence of the stable first water layer.

The simultaneously measured HAS and TPD signals from the $\mathrm{D}_{2} \mathrm{O} / \mathrm{CO} / \mathrm{Ru}(0001)$ system at $\theta_{\mathrm{CO}}=0.6 \mathrm{ML}$ are shown in Fig. 4. Contrary to water on bare $\mathrm{Ru}(0001)$, there is no explicit peak of the first water layer in the TPD spectra as illustrated in Fig. 4(a). Only one peak is observed, with a common leading edge for all coverages. This suggests that a 


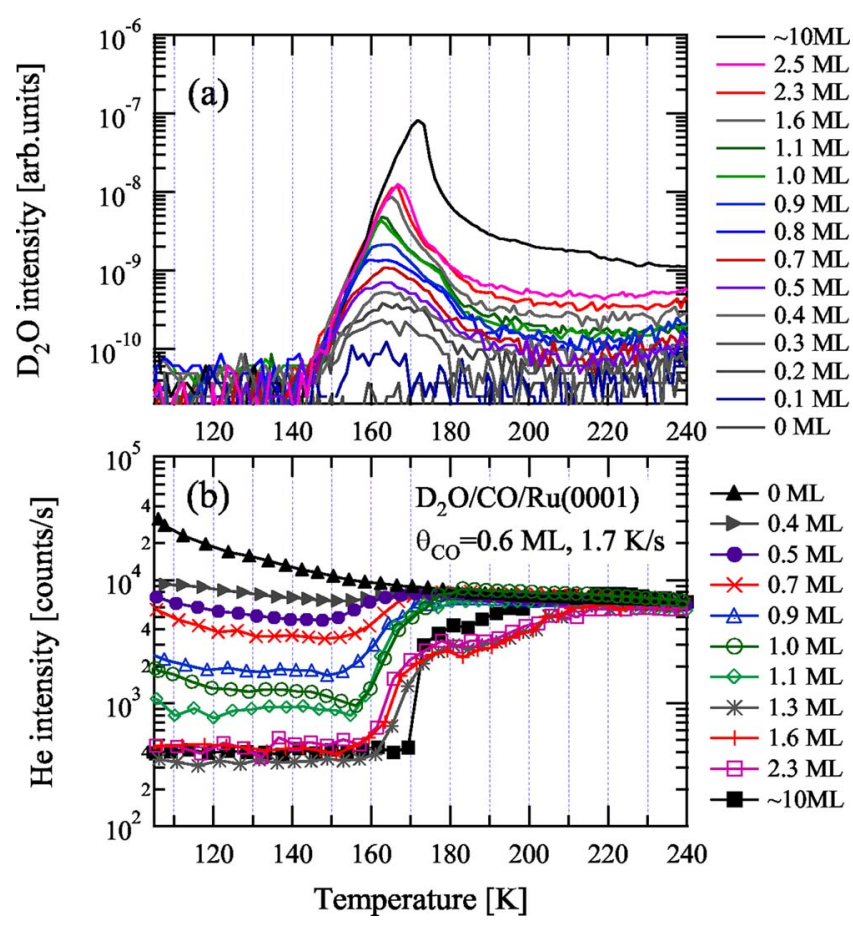

FIG. 4. (Color online) Simultaneous acquisition of (a) TPD and (b) HAS of $\mathrm{D}_{2} \mathrm{O}$ from $\mathrm{D}_{2} \mathrm{O} / \mathrm{CO} / \mathrm{Ru}(0001)$.

stable first water layer does not form on $\mathrm{CO} / \mathrm{Ru}(0001)$, confirming our conclusions for the submonolayer coverage discussed in Sec. III B.

In correspondence with the TPD signal, the specularly reflected $\mathrm{He}$ intensity changes with increasing temperature. At $\theta_{\mathrm{D}_{2} \mathrm{O}}=0 \mathrm{ML}$, the He intensity decreases monotonically with increasing temperature due to the Debye-Waller effect. ${ }^{59-61}$ At low temperature for finite $\theta_{\mathrm{D}_{2} \mathrm{O}}$, the initial $\mathrm{He}$ intensity is weak due to the induced corrugation of the interaction potential by the $\mathrm{D}_{2} \mathrm{O}$ adsorption as discussed in Sec. III B. When the desorption of $\mathrm{D}_{2} \mathrm{O}$ starts from $\sim 140 \mathrm{~K}[$ Fig. 4(a)], the intensity of He starts to increase only for small $\theta_{\mathrm{D}_{2} \mathrm{O}}$. Although the desorption peaks in Fig. 4(a) rise in the same way for all coverages, the temperature at which the $\mathrm{He}$ intensity changes depends strongly on $\theta_{\mathrm{D}_{2} \mathrm{O}}$ as shown in Fig. 4(b). This suggests that the increase of the He intensity at this stage is corresponding to the decrease of the corrugation of the interaction potential by the appearance of the COcovered $\mathrm{Ru}$ substrate (exposure of the $\mathrm{CO}$ adlayer to vacuum) as a result of desorption. ${ }^{53,55,59-61,82,83}$

When initially 1.6 and 2.3 ML of water are adsorbed, the He intensity does not reach the level observed for the bare $\mathrm{CO} / \mathrm{Ru}(0001)$ surface even at $\sim 200 \mathrm{~K}$ as shown in Fig. 4(b), although no clear additional desorption peak is recognized in the corresponding TPD. This suggests either the existence of dissociated species of $\mathrm{D}_{2} \mathrm{O}$ left on the surface or the existence of $\mathrm{D}_{2} \mathrm{O}$ molecules which cannot be discerned with TPD due to the large tail of the multilayer desorption peak. Since we could not observe any desorption feature related to dissociated species such as $\mathrm{D}_{2} \mathrm{O}$ recombination peaks or desorbing hydrogen molecules, the presence of intact $\mathrm{D}_{2} \mathrm{O}$ molecules on the surface is considered to be plausible, in agreement with previous conclusions from Naka-

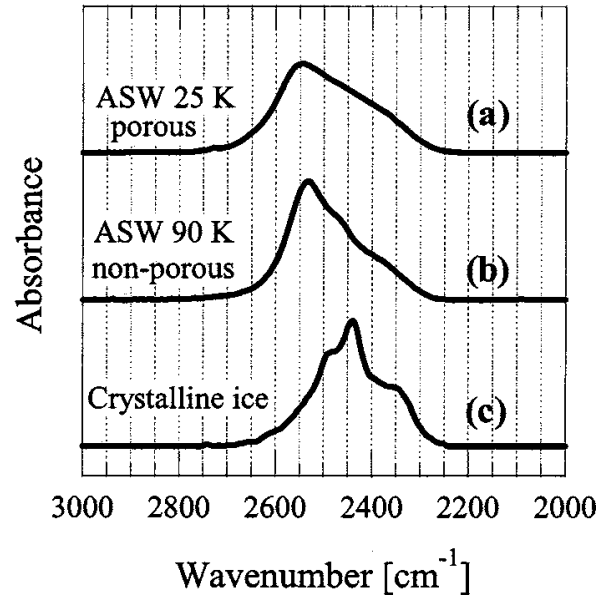

FIG. 5. Typical IRAS spectra of ASW [(a) and (b)] and crystalline ice and (c) with $\theta_{\mathrm{D}_{2} \mathrm{O}}=\sim 25 \mathrm{ML}$. The spectra were normalized by the integral intensity of the absorbance.

mura and Ito. ${ }^{79}$ These remaining $\mathrm{D}_{2} \mathrm{O}$ molecules, which have a binding energy exceeding the water-water binding strengths, are only observed at high $\theta_{\mathrm{D}_{2} \mathrm{O}}$ as shown in Fig. 4(b). Remarkably, the strength of interaction between the remaining $\mathrm{D}_{2} \mathrm{O}$ molecules and the substrate is seemingly higher for 1.6 and 2.3 ML than at both lower and higher coverages, as evidenced by the later recovery of the He intensity. The same component can also be observed in the crystallization experiments of ASW ( $\sim 50 \mathrm{ML})$ discussed in the next section.

\section{Crystallization of ASW}

In this section, we describe the mechanism and kinetics of ASW crystallization and the morphological change of water films involving the crystallization process on bare $\mathrm{Ru}(0001)$ and $(5 \sqrt{3} \times 5 \sqrt{3}) \mathrm{R} 30^{\circ}-\mathrm{CO} / \mathrm{Ru}(0001)$ in Secs. III D 1 and III D 2, respectively. Despite the quite different ASW-substrate interactions between water and $\mathrm{Ru}(0001)$ and $\mathrm{CO} / \mathrm{Ru}(0001)$ as discussed above, the mechanism and kinetics of the ASW crystallization and the morphological change probed by our HAS, IRAS, and ITPD are found to be quite similar. Some differences are apparent in the HAS measurements, the details of which are discussed in Sec. III E.

In order to probe the bulk crystallinity of ASW films, IRAS spectra are analyzed carefully as described in Sec. II. The continuously obtained IRAS spectra during crystallization can be reproduced very well by a sum of contributions from amorphous and crystalline domains, as reported in the literature. $^{28,53}$ This indicates the absence of an intermediate state between ASW and CI from a viewpoint of the infrared vibrational spectroscopy under our experimental time resolution. Typical IRAS spectra of $\sim 25 \mathrm{ML}$ ASW and CI on $\mathrm{Ru}(0001)$ are shown in Fig. 5 where each spectrum is normalized to the integrated absorbance. IRAS spectra of ASW deposited at 25 and $90 \mathrm{~K}$ exhibit some differences as shown in Figs. 5(a) and 5(b). The spectrum at $90 \mathrm{~K}$ is narrower than that at $25 \mathrm{~K}$ and exhibits some small bumps. The differences between these spectra have been interpreted as being due to the degree of porosity in ASW [highly porous for Fig. 5(a) and nonporous for Fig. 5(b)] based on the TPD of the probe 


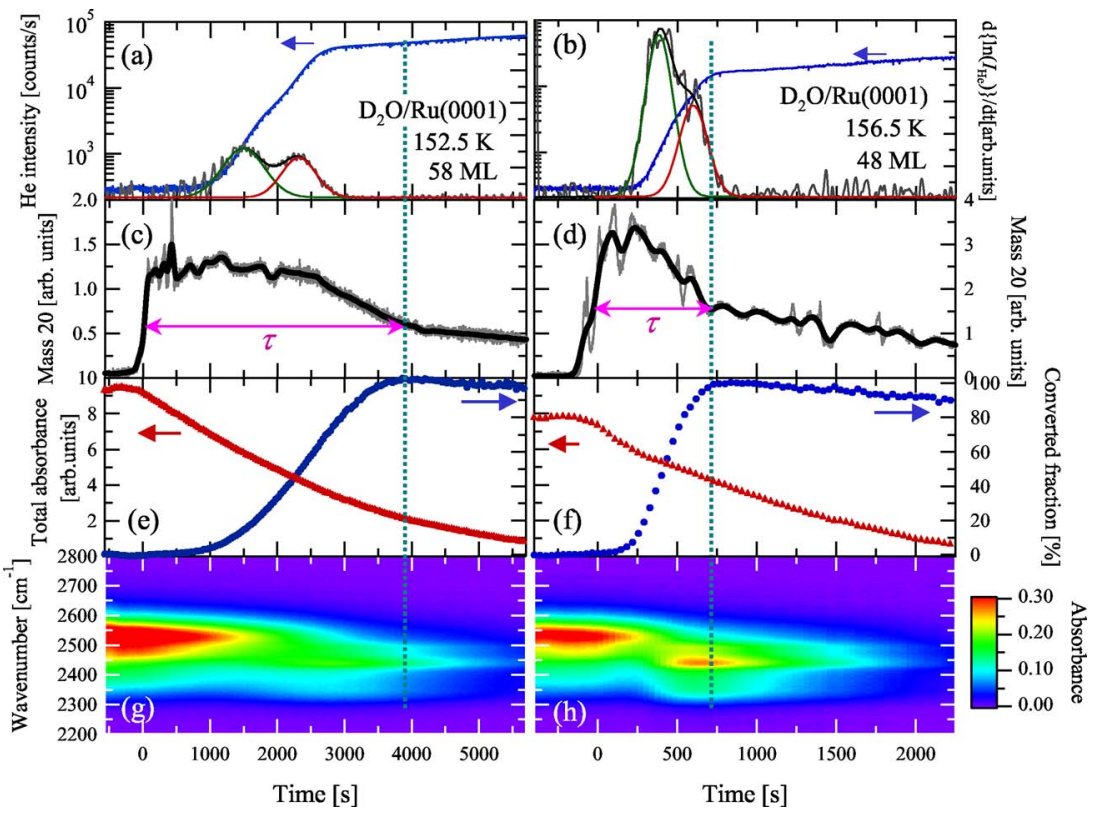

FIG. 6. (Color online) Simultaneous acquisition of HAS, ITPD, and IRAS from initially $\sim 50 \mathrm{ML}$ ASW is adsorbed on Ru(0001) at $152.5 \mathrm{~K}$ (left) and $156.5 \mathrm{~K}$ (right). During the period up to $t=0 \mathrm{~s}$, the temperature increases from $\sim 90 \mathrm{~K}$ to the designed temperature with a heating rate of $\sim 0.2 \mathrm{~K} / \mathrm{s}$. The temperature is then held at the designated temperature. [(a) and (b)] Left axis shows the He beam intensity $I_{\mathrm{He}}$ of the specular reflection (HAS) on a log scale, while the right axis shows $d\left\{\ln \left(I_{\mathrm{He}}\right)\right\} / \mathrm{dt}$ (gray curve; black curve represents the fitting result, green and red curves show two components of $d\left\{\ln \left(I_{\mathrm{He}}\right)\right\} / \mathrm{dt}$.) [(c) and (d)] The desorption rate of $\mathrm{D}_{2} \mathrm{O}$ from $\mathrm{Ru}(0001)$ (ITPD, gray curve; black curve represents average). [(e) and (f)] Total weighted absorbance (summation of integrated absorption of the fraction of ASW and that of CI) is shown in the left axis, while the right axis shows converted fraction of ASW to CI phase derived from the linear fit of IRAS result. [(g) and (h)] IRAS results in the range of OD stretching vibrational mode (see text). Each vertical dotted line represents the moment when $\sim 100 \%$ conversion is achieved in (e) and (f).

molecule of $\mathrm{CH}_{4}$ and IRAS experiments by our group, ${ }^{84}$ in accordance with previous observations of the structural ASW difference. $^{73,74,85}$ As shown in Figs. 5(b) and 5(c), the center of the absorbance peak is located at lower frequency for CI than for ASW due to the stronger hydrogen bonded network of $\mathrm{CI}$ as reported in literature. ${ }^{73-75}$ The shape of the ASW spectrum at $90 \mathrm{~K}$ (nonporous ASW) is nearly identical for all three substrates studied here. The precise shape of the CI spectrum differs slightly depending on the crystallization temperature. The detail and origin of the difference of the CI spectrum shape will be reported in a future publication. A similar observation has been made previously in the TPD study, ${ }^{25,26}$ where differently shaped TPD spectra of probe molecules from converted crystalline ice surface were observed, depending on the condition of the experiment. The difference of the TPD shape has been attributed to the residual amorphous component surrounding the annealed CI grains, which resists conversion to CI. ${ }^{86,87}$

\section{Crystallization mechanism}

Figure 6 shows simultaneous and in situ observations of HAS, ITPD, and IRAS as a function of time for initially deposited ASW films $\left(\sim 50 \mathrm{ML} \mathrm{D}_{2} \mathrm{O}\right)$ on $\mathrm{Ru}(0001)$ at 152.5 and $156.5 \mathrm{~K}$. During the period up to $t=0 \mathrm{~s}$, the temperature increases from $\sim 90 \mathrm{~K}$ to the designated temperature with a heating rate of $\sim 0.2 \mathrm{~K} / \mathrm{s}$. The temperature is then held at the designated temperature. The HAS results depicted by Figs. 6(a) and 6(b) show that the specular HAS intensity increases markedly with time at both temperatures, indicating that morphological changes occur at the surface. Simultaneously, a significant drop in the desorption rate occurs, as evidenced by the ITPD signal in Figs. 6(c) and 6(d). When the water desorption rate drops to about half its initial intensity, the crystallization of ASW has been considered to be complete. ${ }^{17-23,29}$ The time needed to reach this point, indicated as time " $\tau$ " in Fig. 6, has been used to characterize the crystallization kinetics. ${ }^{17-20}$ As a result of the desorption of $\mathrm{D}_{2} \mathrm{O}$ (evident from the ITPD traces), the intensity of $\nu_{\mathrm{OD}}$ in IRAS spectra decreases as shown in Figs. 6(g) and 6(h). As the IR responses of the crystalline and amorphous phases are different as shown in Fig. 5, the fraction of ASW converted into CI can be readily extracted from IRAS spectra as described in Sec. II. The results are shown in Figs. 6(e) and 6(f). Figure 7 shows the results of same measurements as Fig. 6 but conducted on the ASW adsorbed on $\mathrm{CO} / \mathrm{Ru}(0001)$ at $\theta_{\mathrm{CO}}=0.65 \mathrm{ML}$, i.e., $\mathrm{ASW}$ on $(5 \sqrt{3} \times 5 \sqrt{3}) \mathrm{R} 30^{\circ}-\mathrm{CO} /$ $\mathrm{Ru}(0001)$. On this substrate, the details of the interface between ASW and the substrate can be derived from the peak position and intensity of $\nu_{\mathrm{CO}}$. The IRAS spectra in region $\nu_{\mathrm{CO}}$ are additionally shown as Figs. 7(i) and 7(j).

At each temperature and each substrate, the point at which the converted fraction reaches $\sim 100 \%$ coincides with a change in the desorption rate as indicated by the dotted lines in Figs. 6 and 7. This proves explicitly the validity of using ITPD to monitor crystallization, ${ }^{17-23,29}$ and excludes another recently proposed interpretation of ITPD, which attributes the change in the desorption rate in ITPD to a morphological change and/or phase transformation to the liquid/ supercooled-liquid phase. ${ }^{51,52}$

Nucleation of the crystallization at the ASW surface can be ruled out by noting the following observations: during the crystallization process, a drop in ITPD signals [Figs. 6(c), 


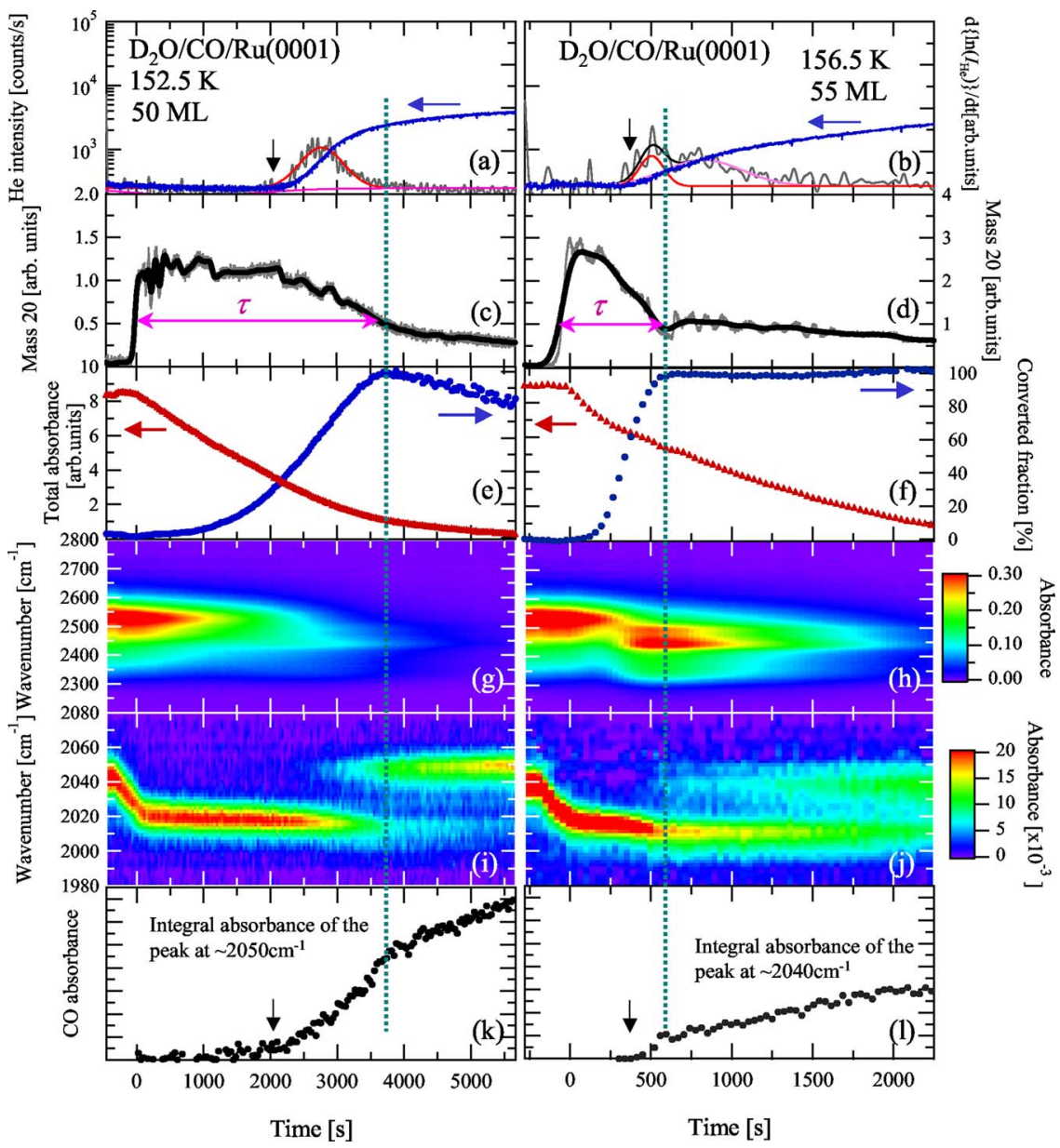

FIG. 7. (Color online) Similar series of data in Fig. 6 but conducted for the initially ASW films $(\sim 50$ ML) adsorbed on a $(5 \sqrt{3} \times 5 \sqrt{3}) \mathrm{R} 30^{\circ}-\mathrm{CO} /$ $\mathrm{Ru}(0001)$ surface. Additionally, the vibrational spectrum in the range of the CO stretching vibrational mode is shown in (i) and (j). The integral intensities of the $\mathrm{CO}$ absorption peak around $\sim 2050$ and $\sim 2040 \mathrm{~cm}^{-1}$ are shown in (k) and (1), respectively.

6(d), 7(c), and 7(d)] by a factor of $\sim 2$ is observed, which is associated with the ASW-CI transition at the surface. It is evident from the data that this drop occurs well beyond the point at which bulk conversion has already significantly occurred, as observed in the IRAS results [Figs. 6(e)-6(h) and 7(e)-7(h)]. A significant decrease of the ITPD signal can be identified well after the onset of IRAS change, i.e., at $\sim 2500$ and $\sim 250$ s for Figs. 6(c) and 7(c) and Figs. 6(d) and 7(d), respectively. Nucleation at the Ru-ASW interface can also be ruled out. If this were to occur, the HAS intensity (which probes the outermost surface) should not change during the initial stages of crystallization, contrary to our observation. These observations indicate that nucleation of the crystalline phase takes place in the bulk of the ASW, presumably through random nucleation processes. This nucleation mechanism has been used to explain the crystallization of ASW on most substrates reported to date based on the analysis of the crystallization kinetics. ${ }^{17-29}$ One marked exception is $\mathrm{ASW}$ on $\mathrm{CI} / \mathrm{Pt}(111)$, for which heterogeneous nucleation was attributed to the template effect of the substrate as a two-dimensional nucleation site for the growth of CI. ${ }^{24,25}$ In the case of $\mathrm{Ru}(0001)$, there has been an expectation of the epitaxial growth of $\mathrm{CI}$ on $\mathrm{Ru}(0001)$ through the modified Bernal-Fowler-Pauling rules due to the small lattice mismatch between the $\mathrm{Ru}(0001)$ substrate and CI. ${ }^{36-38}$ One therefore might expect a similar template effect on $\mathrm{Ru}(0001)$ as well. Our results shown in Fig. 6, however, clearly exclude this template effect on $\mathrm{Ru}(0001)$ under our experimen- tal conditions. Figures 6 and 7 will be discussed in more detail below (Sec. III D 2).

To confirm our conclusion and to obtain a more quantitative understanding of the crystallization mechanism, we have measured the temperature dependence of the crystallization mechanism/process and analyzed the results using theoretical calculations. The ASW-CI conversion at $153 \mathrm{~K}$ as derived from the IRAS spectra is shown in Fig. 8(a). According to the classical model of nucleation and growth of isothermal solid-state phase transformation kinetics, formulated independently by Kolomogorov ${ }^{88,89}$ (1937), Johnson and Mehl $^{90}$ (1939), and Avrami ${ }^{91}$ (1939-1941), the isothermal time dependence of the crystallization mole fraction is given by the following Avrami-type equation: ${ }^{92}$

$$
\chi(\mathrm{t})=100\left[1-\exp \left\{-(k t)^{n}\right\}\right]
$$

where $\chi$ is the converted fraction (\%), $t$ is time $(\mathrm{s}), k$ is a crystallization rate constant, and $n$ is a parameter that depends on the mechanism of the crystallization. The best fit to our results to the above equation is obtained for $n=\sim 3.5$ as shown in Fig. 8(a). When heterogeneous nucleation occurs, $n$ is known to be $\sim 1.4,{ }^{29}$ while $n=\sim 4$ characterizes the mechanism involving spatially random bulk nucleation with a constant nucleation rate in time and isotropic threedimensional (3D) growth of the grains at a constant radial rate. $^{29,92}$ Our derived value of $n=\sim 3.5$ is therefore consistent with the conclusion drawn above that crystallization of 

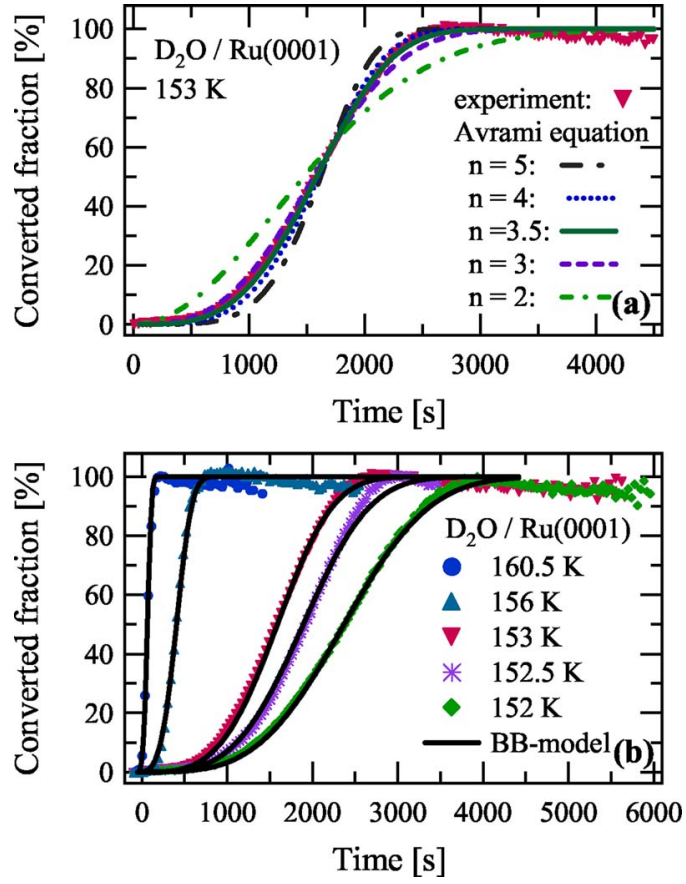

FIG. 8. (Color online) Converted fraction from ASW ( $\sim 50 \mathrm{ML})$ to CI estimated from IRAS fitting analysis. (a) Result at $153 \mathrm{~K}$ is analyzed by the Avrami-type equation (see text), where the equation with $n=3.5$ well reproduce our result. (b) Results at various temperatures are shown as a function of isothermal annealing time. Solid curves are the calculated results based on the BB-model [Backus and Bonn model (Ref. 93)] (see text).

ASW occurs through random nucleation in the bulk followed by effectively isotropic 3D growth.

The above conclusion of the crystallization mechanism enables us to analyze our results by a more quantitative and advanced Avrami theory formulated recently by Backus and Bonn. ${ }^{93}$ The theory includes the following three potentially important effects: (i) the desorption of the material, (ii) the finite nucleation core size, and (iii) the possibility that nucleation occurs at the ASW-substrate interface or the ASWvacuum interface. This theory agrees closely with our experimental results as shown by the solid curves in Fig. 8(b), where a nucleation grain diameter of $3 \mathrm{ML}$ is used ${ }^{20}$ and the bulk nucleation rate and homogeneous growth rate are adjustable parameters. The derived kinetic parameters of the crystallization are summarized in Table. I, with the desorption rate inferred independently from the time-variation of the IRAS total absorbance. The excellent agreement between

TABLE I. The kinetic parameters of bulk nucleation rate $\left(\mathrm{ML}^{3} / \mathrm{s}\right)$ and growth rate $(\mathrm{ML} / \mathrm{s})$ derived from the fitting analysis (see text). The desorption rate $(\mathrm{ML} / \mathrm{s})$ used in the calculation is also shown which is estimated from the time variation of the IRAS total absorbance.

\begin{tabular}{cccc}
\hline \hline $\begin{array}{c}\text { Temperature } \\
(\mathrm{K})\end{array}$ & $\begin{array}{c}\text { Desorption rate } \\
(\mathrm{ML} / \mathrm{s})\end{array}$ & $\begin{array}{c}\text { Growth rate } \\
(\mathrm{ML} / \mathrm{s})\end{array}$ & $\begin{array}{c}\text { Bulk nucleation rate } \\
\left(\mathrm{ML}^{3} / \mathrm{s}\right)\end{array}$ \\
\hline 152.0 & $1.28 \times 10^{-2}$ & $4.3 \times 10^{-2}$ & $7.20 \times 10^{-9}$ \\
152.4 & $1.41 \times 10^{-2}$ & $4.6 \times 10^{-2}$ & $1.30 \times 10^{-8}$ \\
153.0 & $1.33 \times 10^{-2}$ & $4.8 \times 10^{-2}$ & $2.00 \times 10^{-8}$ \\
155.0 & $2.99 \times 10^{-2}$ & 0.10 & $1.85 \times 10^{-7}$ \\
156.0 & $3.31 \times 10^{-2}$ & 0.11 & $2.70 \times 10^{-7}$ \\
160.6 & $2.37 \times 10^{-2}$ & 0.25 & $4.00 \times 10^{-6}$ \\
\hline \hline
\end{tabular}

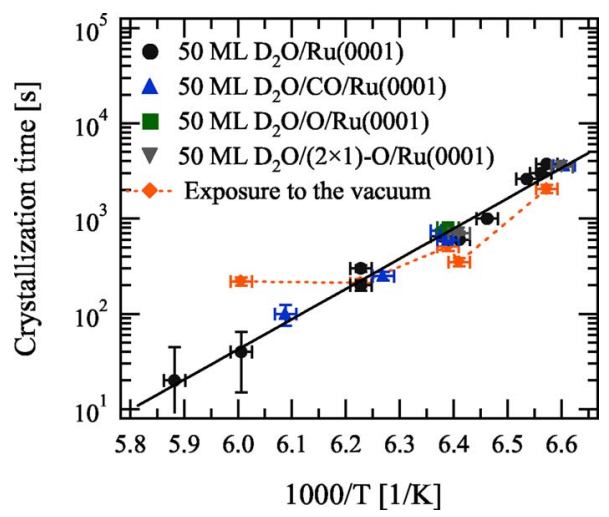

FIG. 9. (Color online) Arrhenius plot of the ASW ( $\sim 50 \mathrm{ML})$ crystallization time (100\% conversion time) derived from IRAS results. The results on $\mathrm{Ru}(0001)$, on $(5 \sqrt{3} \times 5 \sqrt{3}) \mathrm{R} 30^{\circ}-\mathrm{CO} / \mathrm{Ru}(0001)$, on $\mathrm{O}(\sim 0.1 \mathrm{ML}) /$ $\mathrm{Ru}(0001)$, and on $(2 \times 1)-\mathrm{O} / \mathrm{Ru}(0001)$ are shown. The moment of the exposure of the first water layer to the vacuum is also shown by the solid diamond (see text).

the model and the experimental results at different temperatures [Fig. 8(b)] conclusively demonstrates that the crystallization mechanism consists of random nucleation events in the bulk of the material, followed by homogeneous growth.

The Arrhenius-type plot presented in Fig. 9 is based on the time required for the $\sim 100 \%$ conversion from ASW to $\mathrm{CI}$ as determined from IRAS analysis. The derived apparent activation energy for the crystallization of bulk ASW $\left(\theta_{\mathrm{D}_{2} \mathrm{O}}\right.$ $=\sim 50 \mathrm{ML})$ is $650 \pm 25 \mathrm{meV}$, which is similar to previous report of $694 \mathrm{meV}$ based on the ITPD analysis. ${ }^{17}$ Although the crystallization kinetics are known to depend on the substrate material, ${ }^{18,19}$ we find indistinguishable crystallization kinetics for a variety of substrates: $\operatorname{Ru}(0001), \quad(5 \sqrt{3}$ $\times 5 \sqrt{3}) \mathrm{R} 30^{\circ}-\mathrm{CO} / \mathrm{Ru}(0001), \mathrm{O}(\sim 0.1 \mathrm{ML}) / \mathrm{Ru}(0001)$, and $(2 \times 1) \mathrm{O} / \mathrm{Ru}(0001)$, as shown in Fig. 9. An Arrhenius plot prepared from the temperature dependence of the bulk nucleation rate and the growth rate, derived from the fitting analysis shown in Table I, yields activation energies of $E_{\text {nucleation }}$ $=1.56 \mathrm{eV}$ and $E_{\text {growth }}=440 \mathrm{meV}$. Both values are in reasonable agreement with the values previously reported for the crystallization of ASW on $\operatorname{Pt}(111)\left(E_{\text {nucleation }}=1.45 \mathrm{eV}\right.$ and $\left.E_{\text {growth }}=580 \mathrm{meV}\right)$ (Ref. 25) and on $\operatorname{Ir}(111) \quad\left(E_{\text {nucleation }}\right.$ $=1.68 \mathrm{eV}$ and $\left.E_{\text {growth }}=470 \mathrm{meV}\right) .{ }^{27}$ Our derived activation energies $\left(E_{\text {nucleation }}\right.$ and $\left.E_{\text {growth }}\right)$, however, may be only one of several possible combinations of fitting parameters. ${ }^{26}$ For an exact determination, one of the parameters should be set using one of the experimental or theoretical methods as described by Safarik and Mullins for the analysis of surface crystallization of ASW. ${ }^{27}$

\section{Morphological change}

On both substrates, the HAS intensity increases during the crystallization of ASW. The initial HAS intensities in Figs. 6 and 7, after thin film growth, are limited by background counts. Due to the disordered nature of the ASW surface, there is no significant specular intensity as described in Sec. III B. During crystallization, the increase of the HAS intensity over time may be due to two factors: (1) the appearance of CI domains that are sufficiently ordered for efficient He scattering, and (2) the exposure of the substrate domains 
to the vacuum. Indeed, closer inspection of the HAS signal for Fig. 6 reveals the presence of two distinct contributions to the signal, while the HAS signal for Fig. 7(a) consists of one component. This is evident most clearly from the time derivative of the signal shown in Fig. 6 (right hand axis), which shows a double-peaked structure. The first peak occurs at roughly the same time as the onset of crystallization in Fig. 6, and is therefore likely to be related to the appearance of surface crystallinity; the second thus likely represents the exposure of the substrate to the vacuum. As for the HAS results in Fig. 7, the first component that appears with the onset of crystallization seems to be absent or difficult to distinguish from the second component onset, possibly due to the fact that the He count rate is still in the diffuse regime. The second component appears at the same moment as in the case of Fig. 6. The interpretation of the second HAS derivative peak being due to the exposure of the substrate to the vacuum is confirmed by the change of $\nu_{\mathrm{CO}}$ intensity and frequency during crystallization of ASW on $\mathrm{CO} / \mathrm{Ru}(0001)$ shown in Figs. 7(i)-7(1), details of which are discussed below. The origin of the absence of the first component, the different He count rate, in the HAS result of Fig. 7 will be discussed in Sec. III E.

The frequency of $\nu_{\mathrm{CO}}$ at $\sim 2050 \mathrm{~cm}^{-1}\left(\sim 2040 \mathrm{~cm}^{-1}\right)$ in Fig. 7(i) [Fig. 7(j)] rapidly shifts to $\sim 2020 \mathrm{~cm}^{-1}$ $\left(\sim 2015 \mathrm{~cm}^{-1}\right)$ while the temperature is being ramped to the crystallization temperature. This suggests a very rapid change of the local interfacial water structure resulting in a stronger interaction of $\mathrm{CO}$ with water molecules. On the other hand, no significant change of $\nu_{\mathrm{OD}}$ in the water spectrum is observed at the corresponding time. This indicates that only the approximately first monolayer of water molecules surrounding $\mathrm{CO}$ changes the local structure. Note that the absorbance intensity at $\sim 2020 \mathrm{~cm}^{-1}\left(\sim 2015 \mathrm{~cm}^{-1}\right)$ is still large in Fig. 7(i) [Fig. 7(j)], indicating that most of CO molecules remain on on-top site of $\mathrm{Ru}(0001)$ contrary to the case in Fig. 2(h) discussed in Sec. III C 2. This interfacial structural change does not affect the crystallization kinetics, since the ITPD and IRAS results are individually identical to those for bare and CO-precovered $\mathrm{Ru}(0001)$, as shown in Figs. 6(c)-6(h) and 7(c)-7(h). The presence of $\mathrm{CO}$ at the interface is therefore considered not to affect the crystallization mechanism and kinetics as concluded in the previous section.

During the crystallization, a new absorption peak of $\nu_{\mathrm{CO}}$ appears at $\sim 2050 \mathrm{~cm}^{-1}\left(\sim 2040 \mathrm{~cm}^{-1}\right)$ as shown in Fig. 7(i) [Fig. 7(j)]. This peak is typical of $\nu_{\mathrm{CO}}$ when only interfacial $\mathrm{D}_{2} \mathrm{O}$ remains on $\mathrm{CO} / \mathrm{Ru}(0001) . \mathrm{D}_{2} \mathrm{O}$ molecules having a binding energy exceeding the water-water binding strengths are observed, as discussed in Sec. III C, at high initial $\theta_{\mathrm{D}_{2} \mathrm{O}}$ condition as shown in Fig. 4(b). Note that the frequency of $\nu_{\mathrm{CO}}$ of $\mathrm{CO}$ on the fully CO-covered $\mathrm{Ru}(0001)$ surface in the absence of water is $\sim 2055 \mathrm{~cm}^{-1}$ at these temperatures. ${ }^{62}$ The moment when this peak appears coincides temporally with the onset of the HAS increase as indicated by the black arrow in Figs. 7(a), 7(b), 7(k), and 7(i). This confirms the interpretation that the $\mathrm{CO}$-covered surface becomes exposed to the vacuum already at early times. Note that the morphological change resulting in the exposure of the substrate oc-

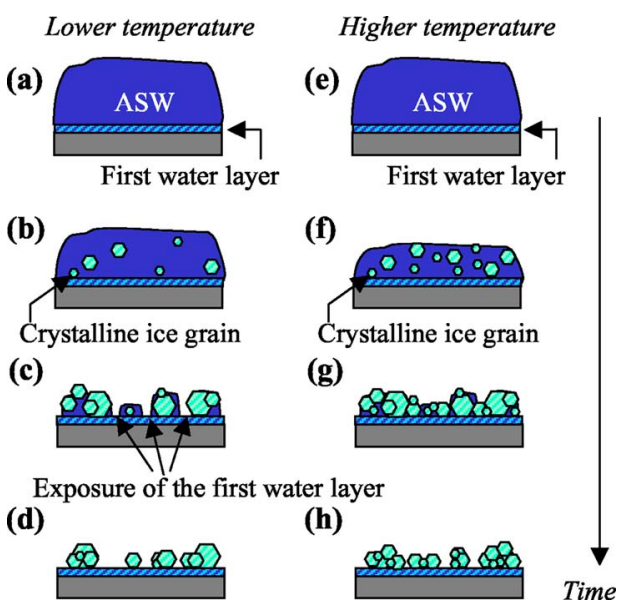

FIG. 10. (Color online) Schematic diagram of the ASW ( $\sim 50 \mathrm{ML})$ crystallization on $\mathrm{Ru}(0001)$ and on $\mathrm{CO} / \mathrm{Ru}(0001)$. The comparison of the crystallization temperature is shown. [(a)-(d)] Lower crystallization temperature. [(e)-(h)] Higher crystallization temperature.

curs during crystallization, i.e., faster than $\tau$, and the event is almost independent of the substrate: the moment of the exposure of the first water layer is quite similar to the onset of the second component of HAS derivative signal in Figs. 6(a) and 6(b). Here, the exposed substrate is not the bare $\mathrm{Ru}(0001)$ or the bare $\mathrm{CO} / \mathrm{Ru}(0001)$ surface (Fig. 6 and Fig. 7 , respectively). On $\mathrm{Ru}(0001)$, the first water layer must be left on the surface under our experimental condition because its desorption temperature lies at much higher temperature, i.e., $\sim 180 \mathrm{~K} .{ }^{35-37,44,49,50,55,77}$ Also on $\mathrm{CO} / \mathrm{Ru}(0001)$, the relatively strongly interacting interfacial structure of $\mathrm{D}_{2} \mathrm{O}$ and $\mathrm{CO}$ is observed to remain on the surface, as the desorption of the "first water layer" from $\mathrm{CO} / \mathrm{Ru}(0001)$ occurs at the even higher temperature of $\sim 190 \mathrm{~K}$ as observed our HAS signals at high coverage condition in Fig. 4.

Both the HAS and the CO IRAS results therefore clearly indicate the exposure of the first water layer when as little as $\sim 40 \%$ of the ASW layer has been converted into CI. This indicates that the large-scale morphological change of the ice surface, which has been previously reported to take place after crystallization, ${ }^{22}$ may occur already during the crystallization process on both substrates under our experimental conditions in Figs. 6 and 7. Because the remaining amount of water corresponds to an average coverage much larger than a few monolayer at the moment when the substrate becomes exposed to the vacuum, 3D grains of CI on the first water layer must be formed. The moment of the exposure of the first water layer to the vacuum as a result of the morphological change by the molecular rearrangement depends on the isothermal temperature $T$, as shown in Fig. 9: the time for the appearance of the first water layer was defined here as the maximum of the second peak of the derivative HAS signal from the case of $\mathrm{Ru}(0001)$ in Figs. 6(a) and 6(b). At high $T$, the first water layer exposure occurs after the crystallization of ASW on $\mathrm{Ru}(0001)$ as on $\mathrm{Pt}(111),{ }^{22}$ whereas at low $T$, the first water layer exposure occurs before the crystallization is complete as schematically shown in Fig. 10. ${ }^{94}$ This suggests a competition between the crystallization and the morphological change of films during the process. Randomly nucle- 
ated CI grains are homogeneously growing at a specific rate depending on $T$ as shown in Figs. 10(b) and 10(f). Simultaneously, molecular rearrangement among the water molecules results in the morphological change. This rearrangement is presumably caused by the different binding energy of water molecules to CI and ASW and is therefore induced by the nucleation of CI grains. The different apparent activation energies for the two competing processes of crystallization and first water layer exposure (see Fig. 9) cause the change in the order of the two processes with varying temperature as schematically shown in Fig. 10.

\section{E. Effect of the interface modification}

As presented in Secs. III B and III C with Figs. 2-4, significant differences exist between the different substrates regarding the interaction of ASW with the substrate, particularly between pristine $\mathrm{Ru}(0001)$ and $\mathrm{CO} / \mathrm{Ru}(0001)$ with $\theta_{\mathrm{CO}}=0.65 \mathrm{ML}$. On the other hand, the mechanism and kinetics of the ASW crystallization have been found to be indistinguishable, independent of the preadsorption of $\mathrm{CO}$ as presented in Sec. III D 1 with Figs. 6-9, which indicates a similar nucleation rate and growth rate of crystalline ice nuclei in ASW films. Finally, the exposure of the first water layer occurs at almost the same moment on the two substrates as a result of the morphological change of the water layers during the crystallization, as discussed in Sec. III D 2 with Figs. 6 and 7. The number of CI grains and the size distribution of grains are therefore considered to be quite similar, independent of the preadsorption of CO. These results suggest that $\mathrm{Ru}(0001)$ covered by $1 \mathrm{ML}$ of water or saturated with $\mathrm{CO}$ have a similar hydrophobic nature, and, as such, exhibit the same behavior for ASW crystallization. These interfaces differ only in a distinct difference of the initial geometric configuration at the interface as discussed in Sec. III B.

On the other hand, as shown in Figs. 6 and 7 the HAS signal exhibits different features during the crystallization, depending on the substrate; one of the two increase components of HAS, "the appearance of CI grain on the surface (described in Sec. III D 2)," is absent (or difficult to distinguish its onset from the other component onset) in the case of the ASW crystallization on $\mathrm{CO} / \mathrm{Ru}(0001)$. This counterintuitive difference of the HAS intensity between Figs. 6 and 7 is considered to originate from the difference of the interaction potential between $\mathrm{He}$ and the substrate. As discussed in Sec. III A with Fig. 1, the corrugation of the interaction potential between $\mathrm{He}$ and $\mathrm{CO} / \mathrm{Ru}(0001)$ is larger than that of $\mathrm{Ru}(0001)$, where the He intensity from $\mathrm{CO} / \mathrm{Ru}(0001)$ is one order of magnitude smaller than that from $\mathrm{Ru}(0001)$. The difference of the HAS intensity between Figs. 6 and 7 contributes almost the same factor of $\sim 10$ and the presence of CO seems to simply shift the whole HAS trace down; the first peak in the derivative signal then remains below noise level for the $\mathrm{CO} / \mathrm{Ru}(0001)$ substrate. The corrugation of the interaction potential is therefore considered to be induced additively by the $\mathrm{D}_{2} \mathrm{O}$ adsorption on $\mathrm{CO} / \mathrm{Ru}(0001)$ as in the case of submonolayer coverage region observed in Fig. 2.

Based on extensive investigations of gas-surface interac- tions reported in the past few decades, ${ }^{95-105}$ the corrugation of the gas-surface interaction potential is known to play an important role on the gas-surface energy transfer process, sticking/trapping event and chemical reactions on the surface. For instance, corrugation of the interaction potential produces an efficient channel for energy transfer during gassurface collision which causes higher sticking, trapping, and reaction probabilities of gas on the surface. Therefore, despite the quite similar crystallization behavior on $\mathrm{Ru}(0001)$ and on $\mathrm{CO} / \mathrm{Ru}(0001)$ as discussed above, the interaction between the CI grains and incoming gas-molecule is considered to be different depending on the substrate. This clearly indicates that HAS is a useful complement to the more common approaches of IRAS and ITPD to characterize the thin crystalline ice surface. Our HAS results indicate the importance of the identification of surface morphology of ice, particularly the corrugation of the interaction potential, by the appropriate noninvasive method such as HAS and/or possibly atomic force microscope as well as the confirmation of phase state by the conventional methods such as IRAS and ITPD for the study of the interaction between gas and ice surface as a investigation at a well-defined system.

\section{CONCLUSIONS}

We have developed a novel combination of measurement techniques of HAS, IRAS, and ITPD to monitor the deposition and the crystallization of thin ASW films on both $\mathrm{Ru}(0001)$ and $\mathrm{CO} / \mathrm{Ru}(0001)$. We have found that the interaction of the $\mathrm{D}_{2} \mathrm{O}$ molecule with the substrate depends on the coverage of $\mathrm{D}_{2} \mathrm{O}$ and preadsorbed $\mathrm{CO}$. Subsequently, the crystallization mechanism of ASW ( $\sim 50 \mathrm{ML})$ has been elucidated. The obtained findings can be summarized as follows:

(1) The modification of the $\mathrm{Ru}(0001)$ surface by the preadsorption of $\mathrm{CO}$ has been found to affect the deposition feature of water layers at the water coverage below $\sim 5$ ML. While ordered first layer structure of water (or with $\mathrm{CO}$ molecules) are formed on the surface below $\theta_{\mathrm{CO}}=0.33 \mathrm{ML}$, disordered structure is formed from the beginning at the $\theta_{\mathrm{CO}}=0.65 \mathrm{ML}$.

(2) The original interpretation of the ITPD signal to monitor the crystallization has been clearly verified for the experimental systems reported here, using our simultaneous experimental measurements of HAS, IRAS and ITPD.

(3) Crystallization of the ASW ( $\sim 50 \quad \mathrm{ML})$ on both $\mathrm{Ru}(0001)$ and $\mathrm{CO} / \mathrm{Ru}(0001)$ proceeds by the bulk random nucleation and homogeneous growth mechanism with an apparent activation energy of $650 \pm 25 \mathrm{meV}$.

(4) The morphological change for the formation of 3D grains of CI has been found to occur during the crystallization process accompanying the exposure of the first water layer to the vacuum on both substrate cases, most notable at relatively low temperatures. 


\section{ACKNOWLEDGMENTS}

One of the authors (T.K.) appreciates the financial support from the SPR System in RIKEN (2003-2005). Another author (M.B.) is grateful for support from the Young Academy of the Royal Dutch Academy of Sciences. This research was also partially supported by RIKEN Research Program "Nanoscale Science and Technology Research" and by the Ministry of Education, Culture, Sports, Science and Technology (MEXT), through "Grant-in-Aid for Young Scientists (B) 17760034, 2005-2007."

${ }^{1}$ Physics of ice edited by V. F. Petrorenko and R. W. Whitworth (Oxford University Press, New York, 1999).

${ }^{2}$ M. Chaplin, http://www.lsbu.ac.uk/water/

${ }^{3}$ The assignment of the glass transition temperature (Refs. 4-8) and whether the glassy water converts directly to the crystal (Refs. 5-10) or firstly melts into the supercooled liquid (Refs. 11 and 12have been extensively investigated and still does not have an agreed view.

${ }^{4}$ G. P. Johari, A. Hallbrucker, and E. Mayer, Nature (London) 330, 552 (1987).

${ }^{5}$ V. Velikov, S. Borick, and C. A. Angell, Science 294, 2335 (2001).

${ }^{6}$ Y. Yue, and C. A. Angell, Nature (London) 427, 717 (2004).

${ }^{7}$ N. Giovambattista, C. A. Angell, F. Sciortino, and H. E. Stanley, Phys. Rev. Lett. 93, 047801 (2004)

${ }^{8}$ A. Minoguchi, R. Richert, and C. A. Angell, Phys. Rev. Lett. 93, 215703 (2004).

${ }^{9}$ M. Fisher and J. P. Devlin, J. Phys. Chem. 99, 11584 (1995).

${ }^{10}$ J. P. Cowin, A. A. Tsekouras, M. J. ledema, K. Wu, and G. B. Ellison, Nature (London) 398, 405 (1999).

${ }^{11}$ P. Jenniskens, S. F. Banham, D. F. Blake, and M. R. McCoustra, J. Chem. Phys. 107, 1232 (1997).

${ }^{12}$ R. S. Smith and B. D. Kay, Nature (London) 398, 788 (1999).

${ }^{13}$ E. F. van Dishoeck, Annu. Rev. Astron. Astrophys. 42, 119 (2004).

${ }^{14}$ P. Ehrenfreund, H. J. Fraser, J. Blum, J. H. E. Cartwright, J. M. GarciaRuiz, E. Hadamcik, A. C. Levasseur-Regourd, S. Price, F. Prodi, and A. Sarkissian, Pestic. Sci. 51, 473 (2003).

${ }^{15}$ P. Ehrenfreund, W. Irvine, L. Becker et al., Rep. Prog. Phys. 65, 1427 (2002)

${ }^{16}$ J. P. D. Abbatt, Chem. Rev. (Washington, D.C.) 103, 4783 (2003).

${ }^{17}$ R. S. Smith, C. Huang, E. K. L. Wong, and B. D. Kay, Surf. Sci. 367, L13 (1996).

${ }^{18}$ P. Löfgren, P. Ahlström, D. V. Chakarov, J. Lausmaa, and B. Kasemo, Surf. Sci. 367, L19 (1996)

${ }^{19}$ P. Löfgren, P. Ahlström, J. Lausma, B. Kasemo, and D. Chakarov, Langmuir 19, 265 (2003).

${ }^{20}$ P. Ahlström, P. Löfgren, J. Lausma, B. Kasemo, and D. Chakarov, Phys. Chem. Chem. Phys. 6, 1890 (2004).

${ }^{21}$ G. Zimbitas, S. Haq, and A. Hodgson, J. Chem. Phys. 123, 174701 (2005).

${ }^{22}$ G. A. Kimmel, N. G. Petrik, Z. Dohnálek, and B. D. Kay, Phys. Rev. Lett. 95, 166102 (2005).

${ }^{23}$ A. S. Bolina, A. J. Wolff, and W. A. Brown, J. Phys. Chem. B 109, 16836 (2005).

${ }^{24}$ Z. Dohnálek, R. L. Ciolli, G. A. Kimmel, K. P. Stevenson, R. S. Smith, and B. D. Kay, J. Chem. Phys. 110, 5489 (1999).

${ }^{25}$ Z. Dohnálek, G. A. Kimmel, R. L. Ciolli, K. P. Stevenson, R. S. Smith, and B. D. Kay, J. Chem. Phys. 112, 5932 (2000).

${ }^{26}$ D. J. Safarik, R. J. Meyer, and C. B. Mullins, J. Chem. Phys. 118, 4660 (2003).

${ }^{27}$ D. J. Safarik and C. B. Mullins, J. Chem. Phys. 121, 6003 (2004).

${ }^{28}$ E. H. G. Backus, M. Grecea, A. W. Kleyn, and M. Bonn, Phys. Rev. Lett. 92, 236101 (2004).

${ }^{29}$ R. S. Smith, Z. Dohnálek, G. A. Kimmel, G. Teeter, P. Ayotte, J. L. Daschbach, and B. D. Kay, in Water in Confining Geometrie, edited by V. Buch and J. P. Devlin (Springer-Verlag, Berlin, 2003), p. 337.

${ }^{30}$ K. P. Stevenson, G. A. Kimmel, Z. Dohnálek, R. S. Smith, and B. D. Kay, Nature (London) 283, 1505 (1999).

${ }^{31}$ F. E. Livingston, J. A. Smith, and S. M. George, Surf. Sci. 423, 145 (1999).

${ }^{32}$ G. A. Kimmel, K. P. Stevenson, Z. Dohnálek, R. S. Smith, and B. D. Kay, J. Chem. Phys. 114, 5284 (2001).
${ }^{33}$ G. A. Kimmel, Z. Dohnálek, K. P. Stevenson, R. S. Smith, and B. D. Kay, J. Chem. Phys. 114, 5295 (2001).

${ }^{34}$ Z. Dohnálek, G. A. Kimmel, P. Ayotte, R. S. Smith, and B. D. Kay, J. Chem. Phys. 118, 364 (2003).

${ }^{35}$ D. L. Doering and T. E. Madey, Surf. Sci. 123, 305 (1982).

${ }^{36}$ P. A. Thiel and T. E. Madey, Surf. Sci. Rep. 7, 211 (1987).

${ }^{37}$ M. A. Henderson, Surf. Sci. Rep. 46, 1 (2002).

${ }^{38}$ S. Dietrich, in Phase Transitions and Critical Phenomena, edited by C. Domb and J. L. Lebowitz (Academic, London, 1988), Vol. 12, p. 2.

${ }^{39}$ D. W. Oxtoby, in Fundamentals of Inhomogeneous Fluids, edited by D. Henderson (Dekker, New York, 1992), p. 407.

${ }^{40}$ G. Held and D. Menzel, Surf. Sci. 316, 92 (1994).

${ }^{41}$ P. J. Feibelman, Science 295, 99 (2002).

${ }^{42}$ A. Michaelides, A. Alavi, and D. A. King, J. Am. Chem. Soc. 125, 2746 (2003).

${ }^{43}$ S. R. Puisto, T. J. Lerotholi, and G. Held, Surf. Rev. Lett. 10, 487 (2003).

${ }^{44}$ D. N. Denzler, S. Wagner, W. Wolf, and G. Ertl, Surf. Sci. 532-535, 113 (2003).

${ }^{45}$ P. J. Feibelman, Chem. Phys. Lett. 389, 92 (2004).

${ }^{46}$ K. Andersson, A. Nikitin, L. G. M. Pettersson, A. Nilsson, and H. Ogasawara, Phys. Rev. Lett. 93, 196101 (2004).

${ }^{47}$ J. Weissenrieder, A. Mikkelsen, J. N. Andersen, P. J. Feibelman, and G. Held, Phys. Rev. Lett. 93, 196101 (2004).

${ }^{48}$ S. Meng, E. G. Wang, Ch. Frischkorn, M. Wolf, and S. Gao, Chem. Phys. Lett. 402, 384 (2005).

${ }^{49}$ S. Haq, C. Clay, G. R. Darling, G. Zimbitas, and A. Hodgson, Phys. Rev. B 73, 115414 (2006).

${ }^{50}$ N. S. Faradzhev, K. L. Kostov, P. Feulner, T. E. Madey, and D. Menzel, Surf. Sci. 415, 165 (2005).

${ }^{51}$ R. Souda, J. Phys. Chem. B 110, 14787 (2006).

${ }^{52}$ R. Souda, J. Phys. Chem. B 110, 17524 (2006).

${ }^{53}$ T. Kondo, H. S. Kato, M. Bonn, and M. Kawai, J. Chem. Phys. 126, 181103 (2007).

${ }^{54}$ T. Kondo, H. S. Kato, T. Yamada, S. Yamamoto, and M. Kawai, Eur. Phys. J. D 38, 129 (2006).

${ }^{55}$ T. Kondo, S. Mae, H. S. Kato, and M. Kawai, Surf. Sci. 600, 3570 (2006).

${ }^{56}$ B. E. Hayden, Vibrational Spectroscopy of Molecules on Surfaces, edited by J. T. Yates Jr. and T. E. Madey (Plenum, New York, 1987).

${ }^{57}$ S. Kneitz, J. Gemeinhardt, and H.-P. Steinrück, Surf. Sci. 440, 307 (1999)

${ }^{58}$ S. H. Payne, J.-S. McEwen, H. J. Kreuzer, and D. Menzel, Surf. Sci. 594, 240 (2005).

${ }^{59}$ Scattering of Thermal Energy Atoms from Disordered Surfaces, Springer Tracts in Modern Physics, edited by B. Poelsema and G. Comsa (Springer-Verlag, Berlin, 1989).

${ }^{60}$ Atomic and Molecular Beam Methods, edited by G. Scoles, D. Laine, and U. Valbusa (Oxford University Press, New York, 1992). Vol. 2.

${ }^{61}$ D. Farias and K. H. Rieder, Rep. Prog. Phys. 61, 1575 (1998).

${ }^{62}$ H. Pfnür, D. Menzel, F. M. Hoffmann, A. Ortega, and A. M. Bradshaw, Surf. Sci. 93, 431 (1980)

${ }^{63}$ P. He, H. Dietrich, and K. Jacobi, Surf. Sci. 345, 241 (1996).

${ }^{64}$ T. E. Madey, Surf. Sci. 79, 575 (1979).

${ }^{65}$ W. Riedl, and D. Menzel, Surf. Sci. 207, 494 (1989).

${ }^{66}$ H. Pfnür, and D. Menzel, Surf. Sci. 148, 411 (1984).

${ }^{67}$ G. Michalk, W. Moritz, H. Pfnür, and D. Menzel, Surf. Sci. 129, 92 (1983).

${ }^{68}$ J.-S. McEwen and A. Eichiler, J. Chem. Phys. 126, 094701 (2007).

${ }^{69}$ G. Blyholder, J. Phys. Chem. 68, 2772 (1964).

${ }^{70}$ C. Stampfl and M. Scheffler, Phys. Rev. B 65, 155417 (2002).

${ }^{71}$ J. Braun, K. L. Kostov, G. Witte, and Ch. Wöll, J. Chem. Phys. 106, 8262 (1997)

${ }^{72}$ S. Bernasek, Heterogeneous Reaction Dynamics (Wiley-VCH, New York, 1995).

${ }^{73}$ J. P. Devlin, J. Geophys. Res. 106, 33333 (2001).

${ }^{74}$ W. Hagen, A. G. G. M. Tielens, and J. M. Greenberg, Chem. Phys. 56, 367 (1981).

${ }^{75}$ J. P. Devlin and V. Buch, J. Phys. Chem. B 101, 6095 (1997).

${ }^{76}$ D. N. Denzler, Ch. Hess, R. Dudek, S. Wagner, Ch. Frischkorn, M. Wolf, and G. Ertl, Chem. Phys. Lett. 376, 618 (2003).

${ }^{77}$ M. M. Thiam, T. Kondo, N. Horimoto, H. S. Kato, and M. Kawai, J. Phys. Chem. B 109, 16024 (2005).

${ }^{78}$ M. Nakamura and M. Ito, Chem. Phys. Lett. 335, 170 (2001).

${ }^{79}$ M. Nakamura and M. Ito, Surf. Sci. 490, 301 (2001). 
${ }^{80}$ H. Ibach and D. L. Mills, Electron Energy Loss Spectroscopy and Surface Vibrations (Academic, New York, 1982).

${ }^{81}$ P. A. Redhead, Vacuum 12, 203 (1962).

${ }^{82}$ T. Kondo, H. Kozakai, T. Sasaki, and S. Yamamoto, J. Vac. Sci. Technol. A 19, 2866 (2001)

${ }^{83}$ T. Kondo, T. Sasaki, and S. Yamamoto, J. Chem. Phys. 118, 760 (2003).

${ }^{84}$ N. Horimoto, H. S. Kato, and M. Kawai, J. Chem. Phys. 116, 4375 (2002).

${ }^{85}$ D. Laufer, E. Kochavi, and A. Bar-Nun, Phys. Rev. B 36, 9219 (1987).

${ }^{86}$ P. Jenniskens and D. F. Blake, Science 265, 753 (1994).

${ }^{87}$ P. Jenniskens and D. F. Blake, Astrophys. J. 473, 1104 (1996).

${ }^{88}$ I. Gutzow and J. Schmelzer, The Vitreous State (Springer-Verlag, Berlin, 1995).

${ }^{89}$ A. N. Kolmogorov, Izv. Akad. Nauk SSSR, Ser. Fiz. 3, 355 (1937).

${ }^{90}$ W. A. Johnson and R. F. Mehl, Trans. AIME 135, 416 (1939).

${ }^{91}$ M. J. Avrami, J. Chem. Phys. 7, 1103 (1939); 8, 212 (1940); 9, 177 (1941).

${ }^{92}$ R. H. Doremus, Rates of Phase Transformations (Academic, New York, 1985).

${ }^{93}$ E. H. G. Backus, and M. Bonn, J. Chem. Phys. 121, 1038 (2004).

${ }^{94}$ The remaining amount of water at the moment when the first water layer is exposed to the vacuum is different depending on the temperature as shown by the total absorbance in Figs. 6 and 7. This indicates that the amount of remaining surface water is not the predominant factor for the moment of the exposure of the first water layer.

${ }^{95}$ J. A. Barker and D. J. Auerbach, Surf. Sci. Rep. 4, 1 (1985).

${ }^{96}$ Surface Reactions edited by R. J. Madix (Springer, Berlin, 1994).

${ }^{97}$ C. T. Rettner, D. J. Auerbach, J. C. Tully, and A. W. Kleyn, J. Phys. Chem. 100, 13021 (1996).

${ }^{98}$ T. Tomii, T. Kondo, T. Hiraoka, T. Ikeuchi, S. Yagyu, and S. Yamamoto, J. Chem. Phys. 112, 9052 (2000).

${ }^{99}$ T. Kondo, T. Tomii, T. Hiraoka, T. Ikeuchi, S. Yagyu, and S. Yamamoto, J. Chem. Phys. 112, 9940 (2000).

${ }^{100}$ T. Tomii, T. Kondo, S. Yagyu, and S. Yamamoto, J. Vac. Sci. Technol. A 19, 675 (2001)

${ }^{101}$ T. Kondo, T. Tomii, S. Yagyu, and S. Yamamoto, J. Vac. Sci. Technol. A 19, 2468 (2001).

${ }^{102}$ M. Bonn, A. W. Kleyn, and G. J. Kroes, Surf. Sci. 500, 475 (2002).

${ }^{103}$ Surface dynamics The Chemical Physics of Solid Surfaces Vol. 11, edited by D. P. Woodruff (Elsevier, Amsterdam, 2003).

${ }^{104}$ T. Kondo, H. S. Kato, T. Yamada, S. Yamamoto, and M. Kawai, J. Chem. Phys. 122, 244713 (2005).

${ }^{105}$ T. Kondo, T. Tomii, and S. Yamamoto, Chem. Phys. 320, 140 (2006). 